\title{
Differential Expression of the Small-Conductance, Calcium- Activated Potassium Channel SK3 Is Critical for Pacemaker Control in Dopaminergic Midbrain Neurons
}

\author{
Jakob Wolfart, Henrike Neuhoff, Oliver Franz, and Jochen Roeper \\ Medical Research Council, Anatomical Neuropharmacology Unit, Department of Pharmacology, Oxford University, Oxford \\ OX1 3TH, United Kingdom
}

\begin{abstract}
The physiological activity of dopaminergic midbrain (DA) neurons is important for movement, cognition, and reward. Altered activity of DA neurons is a key finding in schizophrenia, but the cellular mechanisms have not been identified. Recently, KCNN3, a gene that encodes a member (SK3) of the smallconductance, calcium-activated potassium (SK) channels, has been proposed as a candidate gene for schizophrenia. However, the functional role of SK3 channels in DA neurons is unclear. We combined patch-clamp recordings with single-cell RT-PCR and confocal immunohistochemistry in mouse midbrain slices to study the function of molecularly defined SK channels in DA neurons. Biophysical and pharmacological analysis, single-cell mRNA, and protein expression profiling strongly suggest that SK3 channels mediate the calciumdependent afterhyperpolarization in DA neurons. Perforated patch recordings of DA neurons in the substantia nigra (SN) demonstrated that SK3 channels dynamically control the fre-
\end{abstract}

quency of spontaneous firing. In addition, SK3 channel activity was essential to maintain the high precision of the intrinsic pacemaker of DA SN neurons. In contrast, in the ventral tegmental area, DA neurons displayed significantly smaller SK currents and lower SK3 protein expression. In these DA neurons, SK3 channels were not involved in pacemaker control. Accordingly, they discharged in a more irregular manner compared with DA SN neurons. Thus, our study shows that differential SK3 channel expression is a critical molecular mechanism in DA neurons to control neuronal activity. This provides a cellular framework to understand the functional consequences of altered SK3 expression, a candidate disease mechanism for schizophrenia.

Key words: afterhyperpolarization; dopamine; substantia nigra; A9; ventral tegmental area (VTA); A10; schizophrenia; single-cell RT-PCR; confocal immunohistochemistry
Different subpopulations of dopaminergic (DA) midbrain neurons have been implicated in important brain functions, such as voluntary movement, working memory, and reward (GoldmanRakic, 1999; Kitai et al., 1999; Spanagel and Weiss, 1999). They are also closely involved in the etiology of neuropsychiatric diseases, including schizophrenia (Verhoeff, 1999; Svensson, 2000) and Parkinson's disease (Dunnett and Bjorklund, 1999). Thus, it is of great interest to understand the molecular mechanisms that control electrical activity and neurotransmitter release in DA midbrain neurons and to define the coexpression of ion channel genes that orchestrate their excitability. Dopaminergic neurons, recorded in vivo, discharge either in a single-spike pacemaker mode, in a burst-firing pattern, or show irregular firing (Wilson et al., 1977; Sanghera et al., 1984; Grace and Bunney, 1984a,b). However, in in vitro brain slices, DA neurons display regular, low-frequency pacemaker activity that is generated by intrinsic membrane properties (Sanghera et al., 1984; Kita et al., 1986; Grace and Onn, 1989; Lacey et al., 1989; Kang and Kitai, 1993). The pacemaker duty cycle is initiated by a slow depolarization to threshold followed by a single, broad action potential (AP). The

Received Oct. 5, 2000; revised March 7, 2001; accepted March 9, 2001.

This work was supported by the Medical Research Council. J.R. holds the Monsanto Senior Research Fellowship at Exeter College, Oxford University. We thank Peter Magill for critical reading of this manuscript.

Correspondence should be addressed to Dr. Jochen Roeper, Medical Research Council, Anatomical Neuropharmacology Unit, Oxford University, Mansfield Road, Oxford OX1 3TH, UK. E-mail: jochen.roeper@pharm.ox.ac.uk.

Copyright (C) 2001 Society for Neuroscience $0270-6474 / 01 / 213443-14 \$ 15.00 / 0$ calcium influx that occurs during the AP, activates, among others, small-conductance, calcium-activated potassium (SK) channels (Blatz and Magleby, 1986; Kohler et al., 1996; Vergara et al., 1998; Bond et al., 1999), which in turn generate a large afterhyperpolarization (AHP) (Shepard and Bunney, 1991; Nedergaard et al., 1993; Sah, 1996). This AHP dominates the first part (50-200 msec) of the interspike interval and is apamin-sensitive (Shepard and Bunney, 1991; Ping and Shepard, 1996). The rebound from the AHP initiates another slow depolarization and completes the pacemaker duty cycle. Voltage-gated calcium channels play an important role in the AP-mediated activation of SK channels in DA neurons (Nedergaard et al., 1993; Mercuri et al., 1994; Shepard and Stump, 1999). However, they can also be activated by calcium-mobilizing, metabotropic neurotransmitter receptors (Fiorillo and Williams, 1998, 2000) or by release of calcium from intracellular calcium stores (Seutin et al., 1998, 2000).

The molecular composition of SK channels in identified DA midbrain neurons has not been defined. Recent in situ hybridization studies have demonstrated that mRNA encoding for SK3, one member of the SK family of four related genes (SK1-SK4) (Bond et al., 1999), is highly abundant in DA midbrain nuclei (Kohler et al., 1996; Stocker and Pedarzani, 2000). However, it is unclear whether distinct DA midbrain neuron subpopulations possess variable molecular repertoires and/or densities of their SK channels. Indeed, quantitative autoradiography has indicated significant differences in the density of apamin binding sites between the substantia nigra (SN) (A9) and the ventral tegmental 
area (VTA) (A10) (Mourre et al., 1984). Heterogenous expression of SK channels in distinct DA midbrain neurons might underlie, in part, the functional differences that have been observed between VTA and SN neurons (Grenhoff et al., 1988). In addition, differential SK expression could explain the variable spectrum of effects that have been reported when pharmacologically targeting SK channels in DA midbrain neurons (Shepard and Bunney, 1988, 1991; Gu et al., 1992).

\section{MATERIALS AND METHODS}

Slice preparation. Procedures involving animals were conducted in accordance with the Animals (Scientific Procedures) Act, 1986 (UK), and with the Society for Neuroscience policy on the use of animals in research. C57BL/6J mice (10-14 postnatal days old; Charles River, Margate, UK) were killed by cervical dislocation. Brains were removed quickly, immersed in ice-cold solution, and then blocked for slicing. Thin $(250 \mu \mathrm{m})$ coronal midbrain slices were cut with a Vibroslice (Campden Instruments, London, UK) while being bathed in an ice-cold artificial CSF (ACSF) containing (in $\mathrm{mM}$ ): $125 \mathrm{NaCl}, 25 \mathrm{NaHCO}_{3}, 2.5 \mathrm{KCl}, 1.25$ $\mathrm{NaH}_{2} \mathrm{PO}_{4}, 2 \mathrm{CaCl}_{2}, 2 \mathrm{MgCl}_{2}$, and 25 glucose, bubbled with a mixture of $95 \% \mathrm{O}_{2}$ and $5 \% \mathrm{CO}_{2}$. After sectioning, midbrain slices were maintained submerged in a holding chamber filled with gassed ACSF and allowed to recover for $>30 \mathrm{~min}$ at room temperature $\left(22-24^{\circ} \mathrm{C}\right)$ before the experiment. Midbrain slices containing a clearly defined substantia nigra pars compacta at the level of the rostral interpeduncularis nucleus and the caudal mammillary nucleus (corresponding to levels 2 and 3 in Nelson et al. (1996) were used for the experiments.

Electrophysiological recordings and data analysis. For patch-clamp recordings, midbrain slices were transferred to a chamber and continuously perfused at 2-4 $\mathrm{ml} / \mathrm{min}$ with ACSF bubbled with a mixture of $95 \% \mathrm{O}_{2}$ and $5 \% \mathrm{CO}_{2}$ at room temperature $\left(22-24^{\circ} \mathrm{C}\right)$. Patch pipettes were pulled from borosilicate glass (GC150TF/F; Clark, Reading, UK) with tip resistances between 1.7 and $5 \mathrm{M} \Omega$. Patch pipettes were filled with internal solution containing (in mM): $150 \mathrm{~K}-\mathrm{MeSO} 4$ (KMe), 2 HEPES, and 0.1 EGTA, pH 7.3 (280-300 mOsm). A low level of the calcium buffer EGTA and methylsulphate (KMe) instead of gluconate were used to preserve $\mathrm{Ca}$-dependent $\mathrm{K}$ currents during whole-cell recordings (Zhang et al., 1994). For single-cell PCR experiments, a high potassium chloride pipette solution (KCl) was used containing (in $\mathrm{mM}$ ): $140 \mathrm{KCl}, 5$ HEPES, 0.1 EGTA, and $3 \mathrm{MgCl}_{2}, \mathrm{pH}$ 7.3. For gramicidin-perforated patch-clamp recordings (Akaike, 1996), the patch pipette was tip-filled with $\mathrm{KCl}$ solution, and back-filled with gramicidin-containing $\mathrm{KCl}$ solution $(20-50 \mu \mathrm{g} / \mathrm{ml})$. For cell filling at the end of perforated-patch experiments, we converted the configuration to standard whole-cell by gentle suction monitored by changes in capacitative transients in voltageclamp mode, filled the cell for $2 \mathrm{~min}$, and removed the pipette via the outside configuration. Recordings were made from neurons visualized by infrared differential interference contrast video microscopy with a Newvicon camera (C2400; Hamamatsu, Hamamatsu City, Japan) mounted to an upright microscope (Axioskop FS; Zeiss, Oberkochen, Germany) (Stuart et al., 1993). Recordings were performed in currentclamp and voltage-clamp mode using an EPC-9 patch-clamp amplifier (Heka Elektronik, Lambrecht, Germany). Series resistance was continuously monitored: uncompensated values ranged between 5 and $10 \mathrm{M} \Omega$ for single-cell PCR experiments and between 10 and $30 \mathrm{M} \Omega$ for the other standard whole-cell experiments. The program package Pulse + pulsefit (Heka Elektronik) was used for data acquisition and analysis. Records were digitized at $2-5 \mathrm{kHz}$ and filtered with low-pass filter (Bessel characteristic of $1 \mathrm{kHz}$ cutoff frequency). For extracellular local $(<50 \mu \mathrm{m})$ application of drugs, cells were perfused at a flow rate of $50-100 \mu \mathrm{l} / \mathrm{min}$ under visual control using a quartz pipette $(0.25 \mathrm{~mm}$ inner diameter $)$ attached to a second manipulator and a syringe pump system (World Precision Instruments, Sarasota, FL). Switching between control and drug-containing solutions was controlled by an automated application system (AutoMate Scientific, Oakland, CA). Drugs were diluted in a solution containing (in mM): $10 \mathrm{HEPES}, 145 \mathrm{NaCl}, 2.5 \mathrm{KCl}, 2 \mathrm{CaCl}_{2}, 2$ $\mathrm{MgCl}_{2}$, and 25 glucose, $\mathrm{pH}$ 7.4. Lipophilic substances [gramicidin, tolbutamide, picrotoxin, kynurenic acid, and 1-ethyl-2-benzimidazolinone (1EBIO)] were dissolved in DMSO and diluted 1:1000 to final concentrations. Apart from 1-EBIO (Tocris, Bristol, UK), all drugs were obtained from Sigma (Dorset, UK). A possible shunt of applied and recorded currents caused by activation of ATP-dependent $\mathrm{K}^{+}$channels $\left(\mathrm{K}_{\mathrm{ATP}}\right)$ in standard whole-cell recordings (Liss et al., 1999a) was prevented by tolbutamide $(100 \mu \mathrm{M})$. When using high- $\mathrm{KCl}$ pipette solution, $\mathrm{Cl}$ currents were blocked by $50 \mu \mathrm{M}$ picrotoxin. Excitatory synaptic inputs were blocked by $50 \mu \mathrm{M}$ kynurenic acid during long-term perforated-patch recordings. The degree of rundown of AHP currents $\left(I_{\mathrm{AHP}} \mathrm{s}\right)$ was estimated by fitting a linear regression to the data points recorded under control conditions. This fit predicted the change of control $I_{\mathrm{AHP}}$ throughout the time course of the experiment. In D-tubocurarine (DTC) experiments, the washout $I_{\mathrm{AHP}}$ amplitudes were predicted by the regression fit. The effect of pharmacological agents on $I_{\mathrm{AHP}} \mathrm{S}$ was expressed relative to the predicted control amplitude at the time of analysis. Analysis and plotting was done using IgorPro (WaveMetrics). Voltage-clamp records were filtered off-line $(0.2 \mathrm{kHz})$ and averaged $2-5$ times. To evaluate statistical significance $(p<0.05)$, data were subjected to Student's $t$ tests in Microsoft Excel. The single-cell SK3 protein-current correlation was analyzed according to Fisher in StatView. Numbers are presented as mean values \pm SEM (calculated in Excel if not stated otherwise). Coefficients of variation ( $\mathrm{CVs}$ ) were obtained by dividing the SD of the Gaussian fit by the mean interspike interval (ISI) and expressed as percentage.

Cytoplasm harvest and reverse transcription. For single-cell reverse transcription (RT)-PCR experiments, the patch pipettes were filled with $6 \mu \mathrm{l}$ of autoclaved internal RT-PCR solution as described above (Liss et al., 1999a). At the end of the recording $(<15 \mathrm{~min})$, the cell contents (including the nucleus, in most cases) were aspirated into the patch pipette under visual control $(40 \times$ objective $+2-4 \times$ zoom $)$ by application of gentle negative pressure. Cells were only analyzed further when the whole-cell configuration remained stable throughout the harvesting procedure. Pipettes were then quickly removed from the cell, washed two times through the solution interface, and the pipette contents were immediately expelled into a $0.5 \mathrm{ml}$ Eppendorf tube containing the contents for reverse transcription. First strand cDNA was synthesized for $1 \mathrm{hr}$ at $37^{\circ} \mathrm{C}$ in a total reaction volume of $10 \mu \mathrm{l}$ containing random hexamer primers (Boehringer Mannheim, Mannheim, Germany; final concentration, $5 \mu \mathrm{M}$ ), dithiothreitol (final concentration, $10 \mathrm{mM}$ ), the four deoxyribonucleotide triphosphates (Amersham Pharmacia Biotech, Little Chalfont, UK; final concentration, $0.5 \mathrm{~mm}$ each), $20 \mathrm{U}$ of ribonuclease inhibitor (Promega, Madison, WI), and $100 \mathrm{U}$ of reverse transcriptase (SuperscriptII; Life Technologies, Gaithersburg, MD). The single-cell cDNA was kept at $-70^{\circ} \mathrm{C}$ until PCR amplification.

Multiplex and nested PCR. After reverse transcription, the cDNAs for tyrosine hydroxylase (TH), glutamate decarboxylase (GAD67), and SK1-4 were simultaneously amplified in a multiplex PCR using the following set of primers (from $5^{\prime}$ to $3^{\prime}$ ). Primer pairs for TH, GAD67 were identical to those used in Liss et al. (1999a): SK1-3 PCR products were generated with primers derived from partial (SK1-3) and complete mouse cDNA clones (SK4); SK1 sense: CAGCTGTTCTTGGTGGACAA; antisense: GTCTCCCTGAGAACGTTTGC (710 bp); SK2 sense: AGAAGAACCAGAACATCGGC; antisense: GGTACCTTTCACAAGCTCGG (672 bp); SK3 sense: GGATTCCATGTTTTCGTTGG; antisense: CCAATGGAAAGGAACGTGAT (594 bp); SK4 (accession number AF072884) sense: TTTGATCACCCTGTCCACTG; antisense: AGTCCTTCCTTCGAGTGTGC (806 bp). First multiplex PCR was performed as hot start in a final volume of $100 \mu \mathrm{l}$ containing the $10 \mu \mathrm{l}$ RT reaction, $100 \mathrm{pmol}$ of each primer, $0.2 \mathrm{~mm}$ each dNTP (Pharmacia), $1.8 \mathrm{~mm} \mathrm{MgCl}_{2}, 50 \mathrm{~mm} \mathrm{KCl}, 20$ mM Tris- $\mathrm{HCl}, \mathrm{pH}$ 8.4, and $3.5 \mathrm{U}$ of Gold Taq-polymerase (PerkinElmer Life Sciences, Emeryville, CA) in a PerkinElmer Thermal Cycler 9700 with the following cycling protocol: after $10 \mathrm{~min}$ at $94^{\circ} \mathrm{C}$ for release of the antibody 35 cycles $\left(94^{\circ} \mathrm{C}, 30 \mathrm{sec} ; 58^{\circ} \mathrm{C}, 60 \mathrm{sec} ; 72^{\circ} \mathrm{C} 3 \mathrm{~min}\right)$ of PCR were performed followed by a final elongation period of $7 \mathrm{~min}$ at $72^{\circ} \mathrm{C}$. The nested PCR amplifications were performed in individual reactions, in each case with $2.5 \mu \mathrm{l}$ of the first PCR reaction product under similar conditions with the following modifications: 50 pmol of each primer, $2.5 \mathrm{U}$ Taq polymerase (Life Technologies), $1.5 \mathrm{mM} \mathrm{MgCl}_{2}$, and a shorter extension time $(60 \mathrm{sec})$ using the following primer pairs: SK1 sense: CACTATCGCTTCACGTGGAC; antisense: GAAGGTGATGGAGATGAGCC; SK2 sense: ACTATGCGCTTATCTTCGGC; antisense: GCCGTCCATGTGAACGTATA; SK3 sense: GCCATGACCTACGAGCGTAT; antisense: GTCTTCATGACGAATCGGGT; SK4 sense CTGTACATGAACACGCACCC; antisense: GTTGAACTCCAGCTTCCGAG. To investigate the presence and size of the amplified fragments, 15 $\mu \mathrm{l}$ aliquots of PCR products were separated and visualized in ethidium bromide-stained agarose gels $(2 \%)$ by electrophoresis. The predicted sizes (in base pairs) of the PCR-generated fragments were 377 (TH), 702 (GAD67), 375 (SK1), 310 (SK2), 290 (SK3), and 285 (SK4). All individual PCR products were verified several times $(n>3)$ by direct sequenc- 
ing or subcloning and sequencing. For semiquantitative single-cell RTPCR of SK1, SK2, and SK3 mRNA, we generated serial dilutions $(1 / 2$, $1 / 4,1 / 8,1 / 16,1 / 32 /, 1 / 64)$ of single-cell cDNA pools. Each dilution was used as template in a nested PCR $(2 \times 35$ cycles $)$ with SK1, SK2, and SK3 primers, respectively, as described above, and detection thresholds were analyzed using agarose gel electrophoresis (Franz et al., 2000).

$R N A$ isolation and cDNA preparation for control reactions. poly(A) ${ }^{+}$ RNA was prepared from ventral midbrain and lung tissue of 14-d-old C57BL/6J mice using the Micro-FastTrack Kit (Invitrogen, San Diego, CA). The reverse transcription was performed with $500 \mathrm{ng}$ of poly(A) ${ }^{+}$ RNA as described above. For the positive controls performed in parallel with each single-cell amplification, the resulting brain and lung cDNA stock was diluted 10,000-fold, and $1 \mu \mathrm{l}$ was used as template for the PCR reaction. All PCR fragments were detected routinely in the positive control with the PCR protocol described above. Negative controls were performed in parallel to single-cell experiments excluding only the harvesting procedure and resulted in no detectable bands. To probe for possible amplification of genomic DNA from the harvested single nuclei, single-cell mPCR amplifications were performed without previous reverse transcription. For all analyzed neurons $(n=5)$, no PCR products were detectable. When possible, primer pairs were designed to be intron-spanning.

Immunocytochemistry and confocal microscopy. Neurons in $250 \mu \mathrm{m}$ midbrain slices were recorded for $2-5 \mathrm{~min}$ in the whole-cell configuration with a pipette solution described above $(\mathrm{KMe})$ containing $0.2 \%$ neurobiotin. Pipettes were removed via the outside-out configuration. Control slices and those containing filled neurons were fixed with $4 \%$ paraformaldehyde in PBS, pH 7.4, for $30 \mathrm{~min}$ at room temperature. Subsequently, fixative was removed with four washes of PBS solution. Slices were treated with $1 \%$ Na-borohydride (Sigma) dissolved in PBS for 10 min to reduce unreacted aldehydes and again washed four times in PBS for $5 \mathrm{~min}$. To avoid unspecific bindings of immunoreagents, slices were treated for 20 min with a blocking solution containing $10 \%$ horse serum, (Vector Laboratories, Burlingame, CA), $0.2 \%$ BSA, and 0.5\% Triton X-100 (Sigma) for permeabilization of the cell membranes in PBS. The blocking solution was removed with two washes of PBS. Primary antibodies [sheep anti-TH; 1:1000; Chemicon, Temecula, CA; rabbit antiSK3 (1:1000), Alomone Labs, Jerusalem, Israel] were applied overnight in a carrier solution consisting of $1 \%$ horse serum, $0.2 \%$ BSA, and $0.5 \%$ Triton X-100 in PBS. Afterward, slices were washed four times in PBS for $5 \mathrm{~min}$ and then incubated with the following secondary antibodies: Alexa 488 goat anti-sheep IgG (1:1000; Molecular Probes); avidin-Cy3 (1:1000; Amersham Pharmacia Biotech), and goat anti-rabbit Cy5 (1: 1000; Amersham Pharmacia Biotech) for $90 \mathrm{~min}$ at room temperature in $0.5 \%$ Triton X-100 in PBS. Subsequently, slices were washed six times in PBS for $5 \mathrm{~min}$ and mounted in Vectashield mounting medium (Vector Laboratories) to prevent rapid photo bleaching. Slices were analyzed using a Zeiss LSM 510 confocal laser-scanning microscope. Fluorochromes were excited with an Argon laser at $488 \mathrm{~nm}$ (Alexa; green) using a BP505-530 emission filter, with a HeNe laser at $543 \mathrm{~nm}$ (Cy3; red) in combination with a BP560-615 emission filter and HeNe laser at $633 \mathrm{~nm}$ (Cy5; blue) and a long-pass 650 emission filter. To eliminate any crosstalk of signals, the multitracking configuration of the LSM 510 was used. For all images, the SK3 immunosignal was shown in red color coding, neurobiotin-filled neurons were shown in blue color coding, and $\mathrm{TH}$ staining was shown in green color coding. Images were taken at a resolution of $1024 \times 1024$ pixels with either a Plan-Neofluar $10 \times / 0.3$, Plan-Neofluar $20 \times / 0.5$, Plan-Apochromat $40 \times / 1.3$ Oil Phase 3 , or a Plan-Apochromat $63 \times / 1.4$ Oil Phase 3 Zeiss objective, respectively, using the LSM 510 software 2.5. If not specified otherwise, figures represent overlaid stacks of 12 scanned images in $1 \mu \mathrm{m}$ increments. The specificity of SK3 immunosignal in fixed midbrain sections was ascertained by antigen peptide-blocking experiments. For negative control, 1 $\mu \mathrm{g}$ of SK3 antibody and $1 \mu \mathrm{g}$ of peptide were preincubated for $1 \mathrm{hr}$ at room temperature. This coincubation resulted in no detectable immunoreactivity (data not shown). In addition, incubation with the second antibodies only also showed no detectable immunosignals.

Quantification of the SK3 immunostaining signal. Neurons were scanned with a $40 \times / 1.3$ Oil Phase 3 lens using a $4 \times$ zoom. For quantification, confocal settings were chosen to ensure that both the low SK3 signal intensity of VTA as well as the high SK3 signal intensity of SN neurons were fully resolved within the dynamic range of detection (8 bit, $0-255$ ), and no loss or saturation of signal did occur. Subsequently, all neurons were scanned at the level of the largest somatic transverse section using these defined confocal settings consisting of identical detector gain,
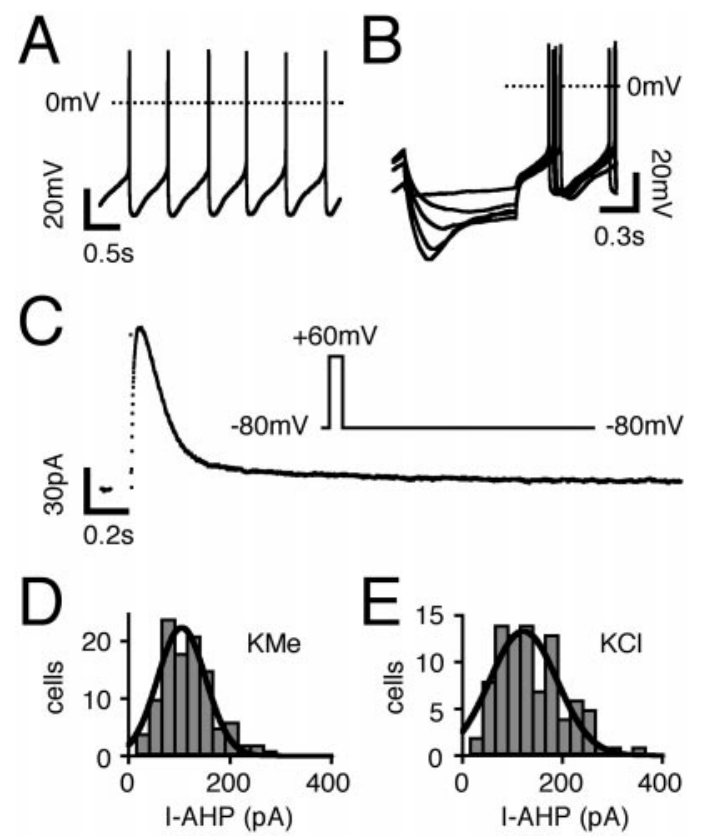

Figure 1. Electrophysiological profile and $I_{\mathrm{AHP}} \mathrm{s}$ in SN DA neurons. $A$, Whole-cell, current-clamp recording of spontaneous pacemaker activity $(1.5 \mathrm{~Hz})$. Note pronounced AHP after single action potentials. $B$, Overlay of voltage responses to hyperpolarizing current injections of increasing intensity. Note prominent "sag" component mediated by $I_{\mathrm{h}}$ activation. $C$, Whole-cell, voltage-clamp recording of an $I_{\mathrm{AHP}}$, activated by a hybrid clamp protocol (inset). $D, E$, Frequency distributions of $I_{\mathrm{AHP}}$ peak amplitudes, recorded with $\mathrm{KMe}(D)$ or high $\mathrm{KCl}(E)$ pipette solutions, were well described by single Gaussian functions with mean $I_{\mathrm{AHP}}$ amplitudes of $105 \pm 6 \mathrm{pA}(n=108)$ and $122 \pm 10 \mathrm{pA}(n=89)$, respectively.

amplifier gain, amplifier offset, pinhole diameter, excitation (laser power), scan mode and speed (line scan), $4 \times$ averaging, frame size $(1024 \times$ 1024,8 bit), $4 \times$ zoom. In these images, regions of interest (ROIs) were drawn surrounding the somata of the scanned neurons. For each ROI that corresponded to the total somatic area of the analyzed neuron, the frequency distribution of SK3 signal intensity was analyzed using LSM 510 software. These frequency distributions of SK3 immunosignal intensity were well described by Gaussian functions to determine their mean intensity using Igor Pro software. In addition, SK3 background noise levels were scanned in five cell-free regions of each slice. A total of 76 slices from 50 mice at $10-14$ postnatal days were analyzed. The absolute background noise levels were similar in VTA $(16.2 \pm 2.4 ; n=23)$ and SN $(17.9 \pm 1.4 ; n=49)$. However, to account even for small variances in the SK3 background noise between different slices, the SK3 signal intensities of individual neurons (determined by ROIs) were normalized to the averaged background signal in the same slice and compared with the $I_{\mathrm{AHP}}$ amplitudes determined in the same cell.

\section{RESULTS}

\section{Biophysical properties of AHP currents in DA SN neurons}

The electrophysiological properties of identified DA midbrain neurons in midbrain slices of C57BL/6J mice (10-14 d) were analyzed using patch-clamp techniques. Current-clamp recordings of DA neurons in the $\mathrm{SN}$ revealed spontaneous, lowfrequency, pacemaker activity (Fig. 1A). A large "sag" component, which is mediated by the activation of $I_{\mathrm{h}}$ channels, was observed after injection of hyperpolarizing currents (Fig. 1B). These two phenomena constitute the well described biophysical fingerprint of DA SN neurons (Sanghera et al., 1984; Grace and Onn, 1989; Lacey et al., 1989; Yung et al., 1991; Richards et al., 1997). In previous studies (Liss et al., 1999a,b; Franz et al., 2000), we have demonstrated using single-cell RT-PCR that neurons 
with these properties express tyrosine hydroxylase mRNA and therefore, possess a dopaminergic phenotype. In accordance with previous studies in mice (Sanghera et al., 1984) and other species (Grace and Onn, 1989; Lacey et al., 1989; Grace, 1991; Yung et al., 1991; Richards et al., 1997), mouse DA SN neurons displayed large and prolonged AHPs that dominated the first part of the interspike interval during pacemaker discharge. To study the currents involved in the AHP in a more controlled and quantitative manner, we used a variant of the hybrid clamp method introduced by Lancaster and Adams (1986). The membrane was depolarized from a holding potential of -80 to $60 \mathrm{mV}$ for 100 msec, to induce unclamped spikes. Subsequently, the membrane potential was stepped back to $-80 \mathrm{mV}$ to record the AHP currents $\left(I_{\mathrm{AHP}} \mathrm{s}\right)$ under voltage-clamp conditions. This method has been used successfully to delineate conductances that contribute to the AHP complex in other neurons (Storm, 1989; Pedarzani and Storm, 1993; Sah, 1996). Because calciumactivated channels are known to play a dominant role in the AHP, we used intracellular pipette solutions with a low calciumbuffering capacity ( $0.1 \mathrm{~mm}$ EGTA) to minimize nonphysiological calcium buffering. Indeed, conventional pipette solutions containing $10 \mathrm{~mm}$ EGTA reduced the AHP currents elicited by the hybrid clamp protocol (data not shown). In DA SN neurons, the hybrid protocol evoked AHP outward currents that peaked $\sim 40-$ $200 \mathrm{msec}$ after the depolarizing voltage step and then slowly decayed (Fig. $1 C$ ). The $I_{\mathrm{AHP}}$ peak amplitudes were normally distributed around a mean of $100 \mathrm{pA}(105 \pm 6 \mathrm{pA}$ at $-80 \mathrm{mV}$; $n=108$ ) using a KMe-based pipette solution (Fig. 1D) and had a slightly larger mean $(122 \pm 10 \mathrm{pA}$ at $-80 \mathrm{mV} ; n=89 ; p<0.01)$ using a KCl-based pipette solution (Fig. $1 E$ ). The single Gaussian distributions of $I_{\mathrm{AHP}}$ peak amplitudes obtained with both pipette solutions in standard whole-cell recordings in DA SN neurons might indicate that these neurons express a stereotypical set of ion channels mediating the $I_{\mathrm{AHP}} \mathrm{s}$.

The decay of the $I_{\mathrm{AHP}} \mathrm{S}$ was dominated by one component with time constants in the range of $100-200 \mathrm{msec}$ (Fig. 2A,B) that corresponds to the "medium" $I_{\mathrm{AHP}}$ (Sah, 1996). This medium $I_{\mathrm{AHP}}\left(\mathrm{m} I_{\mathrm{AHP}}\right)$ decayed with a mean time constant of $135 \pm 7$ msec $(n=105)$ (Fig. $2 A)$ in KMe solution and had a slower time constant in $\mathrm{KCl}$ solutions of $174 \pm 11 \mathrm{msec}(n=88 ; p<0.001)$ (Fig. $2 B)$. In addition, a minor slow component $(14.1 \pm 0.5 \%$ of the total $I_{\mathrm{AHP}}$ amplitude; $n=181$ ) with time constants in the range of $0.5-2.5 \mathrm{sec}$ was present $(\mathrm{KMe}, 1.1 \pm 0.1 \mathrm{sec} ; n=93 ; \mathrm{KCl}$, $1.1 \pm 0.1 \mathrm{sec} ; n=56)$. Removal of extracellular calcium almost completely abolished the $\mathrm{m} I_{\mathrm{AHP}}\left(12 \pm 5 \%\right.$ residual fitted $\mathrm{m} I_{\mathrm{AHP}}$; $n=7)$ (Fig. $2 C)$, but did not affect the slow $I_{\mathrm{AHP}}\left(\mathrm{s} I_{\mathrm{AHP}}\right)(103 \pm$ $12 \%$ residual fitted $\mathrm{s} I_{\mathrm{AHP}} ; n=7$ ) (Fig. $2 C$ ). The calcium sensitivity of the $\mathrm{mI}_{\mathrm{AHP}}$ and its reversal potential $(-100 \pm 5 \mathrm{mV} ; n=$ 5; data not shown) indicates that this current is mediated by calcium-dependent potassium channels. To gain more insight into the calcium sensitivity of the $\mathrm{m}_{\mathrm{AHP}}$ and the contribution of SK channels, we used 1-EBIO, a compound that stabilizes the interaction of the SK channel and its gating modifier calmodulin and thereby increases the open probability of SK channels (Xia et al., 1998; Oliver et al., 2000; Pedarzani et al., 2000; Syme et al., 2000). Application of $2 \mathrm{~mm} 1$-EBIO potentiated the $I_{\mathrm{AHP}}$ amplitudes by a factor of $1.7 \pm 0.1$ (control, $114 \pm 20 \mathrm{pA}$; $1-\mathrm{EBIO}, 186 \pm 29 \mathrm{pA}$; $n=5 ; p=0.001)$ and increased the decay time constant approximately threefold (control, $14 \pm 29 \mathrm{msec}$; 1-EBIO, $412 \pm 59 \mathrm{msec}$; $n=5 ; p<0.001$ ), consistent with the role of 1-EBIO in stabilizing the open state of SK channels (Fig. 2D). These results demonstrate that calcium-activated $\mathrm{K}^{+}$channels, most probably of
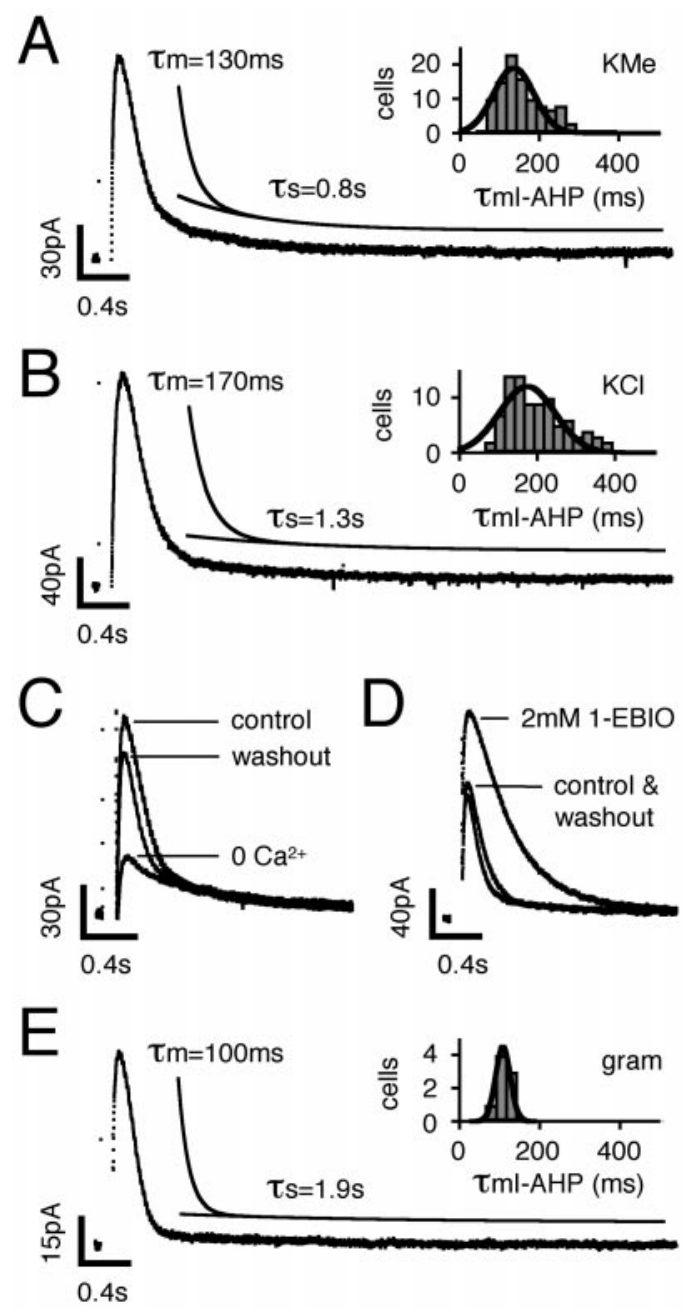

Figure 2. $\quad \mathrm{m}_{\mathrm{AHP}} \mathrm{S}$ in $\mathrm{SN}$ DA neurons are calcium- and 1-EBIO-sensitive. $A, B$, Whole-cell voltage-clamp $I_{\mathrm{AHP}}$ recordings. $I_{\mathrm{AHP}}$ decay was best described with biexponential functions with a medium $(\sim 150 \mathrm{msec})$ and a slow $(\sim 1 \mathrm{sec})$ time constant $(\tau \mathrm{m}$ and $\tau \mathrm{s})$. The medium component accounted for $80 \%$ of the $I_{\mathrm{AHP}}$ amplitude $(79 \pm 10 \% ; n=181)$. Frequency distributions of $\tau \mathrm{m}$ values could be fitted with single Gaussian functions (insets) with a mean $\tau \mathrm{m}$ of $135 \pm 7 \mathrm{msec}(A, \mathrm{KMe} ; n=105)$ and $174 \pm 11 \operatorname{msec}(B, \mathrm{KCl} ; n=88)$, respectively. Mean $\tau$ s values (data not shown) were $1.1 \pm 0.1 \mathrm{sec}$ for both solutions ( $\mathrm{KMe}, n=93 ; \mathrm{KCl}, n=56)$. $C, \mathrm{mI}$ AHPs were dependent on extracellular calcium. Removal of extracellular calcium $\left(0 \mathrm{Ca}^{2+}\right)$ reversibly blocked $88 \pm 5 \%$ of the fitted $\mathrm{mI}_{\mathrm{AHP}}$ amplitude $(n=7)$, but had no effect on the slow $I_{\mathrm{AHP}} D, 1-\mathrm{EBIO}$, an SK channel activator, reversibly increased $I_{\text {AHP }}$ amplitudes and slowed the $I_{\mathrm{AHP}}$ decay. $E, I_{\mathrm{AHP}} \mathrm{s}$ recorded with gramicidin-perforated recordings (gram) had smaller amplitudes $(46 \pm 4 \mathrm{pA} ; n=8)$ compared with those recorded in the whole-cell mode (Fig. 1), but similar $\tau \mathrm{m}$ values $(108 \pm 9$ msec; $n=8$ ).

the small-conductance (SK) type, mediate the dominant, medium $I_{\mathrm{AHP}}$ in DA SN neurons. SK channels possess no intrinsic voltage dependence, and their open probability is coupled to the changes in intracellular calcium concentrations (Hirschberg et al., 1998, 1999; Xia et al., 1998), which in turn, are orchestrated by the interaction of voltage-dependent calcium channels, intracellular calcium pools, calcium pumps, and buffers (Berridge, 1998). Because this delicate interplay of calcium handling mechanisms is likely to be distorted in the standard whole-cell configuration, the gramicidin-perforated patch method (Akaike, 1996) was also used to study $I_{\mathrm{AHP}} \mathrm{S}$ in DA SN neurons. The hybrid clamp pro- 

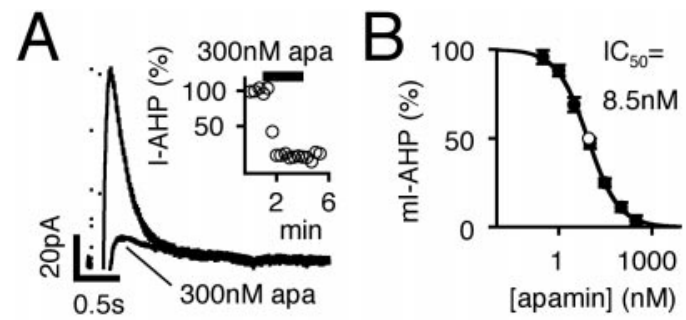

C
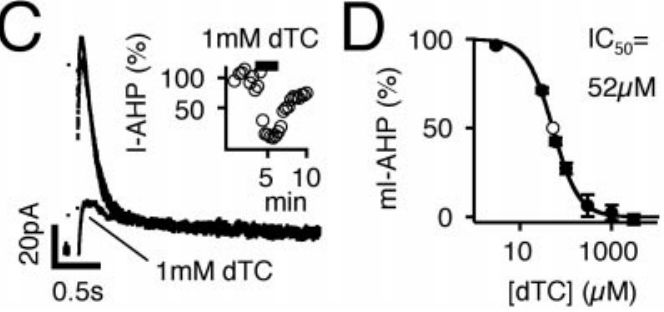

Figure 3. $\mathrm{m}_{\mathrm{AHP}} \mathrm{s}$ in $\mathrm{SN} \mathrm{DA}$ neurons are apamin- and D-tubocurarinesensitive. Whole-cell voltage-clamp recordings of SN DA neurons. $A$, The medium $I_{\mathrm{AHP}}$ was completely blocked by $300 \mathrm{nM}$ apamin (apa), whereas the slow $I_{\mathrm{AHP}}$ component was not affected. Inset shows time course of normalized $I_{\mathrm{AHP}}$ amplitudes during the experiment. $B$, The mean doseresponse for apamin inhibition was well described by a single Hill function with an $\mathrm{IC}_{50}$ of $8.5 \mathrm{~nm}$ and a Hill coefficient of $0.9(n=53)$. $C$, The medium $I_{\mathrm{AHP}}$ was also selectively blocked by $1 \mathrm{mM}$ DTC. In contrast to apamin, the inhibition by DTC was readily reversible (inset). Mean doseresponse for DTC inhibition was well described by a single Hill function with an $\mathrm{IC}_{50}$ of $52 \mu \mathrm{M}$ and a Hill coefficient of $1.5(n=30)$.

tocol elicited $\mathrm{m} I_{\mathrm{AHP}} \mathrm{S}$ with significantly smaller amplitudes $(46 \pm$ $4 \mathrm{pA} ; n=8 ; p<0.0001)$ but similar decay kinetics $(108 \pm 9 \mathrm{msec}$; $n=8$ ) (Fig. $2 E$ ) in gramicidin-perforated patch recordings compared with those elicited with $0.1 \mathrm{~mm}$ EGTA KMe solutions in the standard whole-cell mode $(p>0.01)$. In summary, these results indicate that calcium- and 1-EBIO-sensitive $\mathrm{K}^{+}$channels mediate the dominant, medium $I_{\mathrm{AHP}}$ under conditions of intact calcium handling in DA SN neurons.

\section{Pharmacology of SK channels in DA midbrain neurons}

To gain more insight into the type of $\mathrm{K}^{+}$channel activity that underlies the calcium- and 1-EBIO-sensitive $\mathrm{m} I_{\mathrm{AHP}}$, quantitative pharmacological experiments on DA SN neurons were performed. Apamin, a bee venom that selectively blocks SK channels (Romey et al., 1984; Ishii et al., 1997a), inhibited the $\mathrm{mI}_{\mathrm{AHP}}$ in low nanomolar concentrations but did not affect the calciuminsensitive $\mathrm{s} I_{\mathrm{AHP}}$ (Fig. 3A). This demonstrated that the $\mathrm{m} I_{\mathrm{AHP}}$ is indeed mediated by SK channels. The onset of inhibition by apamin occurred within seconds but was not reversible within washout periods of $\sim 10 \mathrm{~min}$. The apamin concentration-response curve of the mean $\mathrm{m}_{\mathrm{AHP}} \mathrm{S}$ was well described with a single Hill function that had an $\mathrm{IC}_{50}$ of $8.5 \mathrm{~nm}$ and a Hill coefficient of 0.9. $\left(n=53\right.$; mean $\mathrm{IC}_{50}$ of apamin $\left.=9.2 \pm 0.7 \mathrm{~nm} ; n=24\right)$ (Fig. $3 B)$. The $\mathrm{IC}_{50}$ in the low nanomolar range is similar to that described for recombinant SK3 channels (Ishii et al., 1997a). In contrast, recombinant SK2 channels display a higher apamin sensitivity with an $\mathrm{IC}_{50}$ in the picomolar range (Kohler et al., 1996; Ishii et al., 1997a). Thus, these data do not support a contribution of SK2 channels in the $I_{\mathrm{AHP}}$ of DA SN neurons. Based on the conflicting results on the apamin sensitivity of SK1 channels (Kohler et al., 1996; Ishii et al., 1997a; Shah and Haylett, 2000; Strobaek et al., 2000), it is difficult to assess its possible contribution to the native SK channel in DA neurons. The toxin DTC has been shown to bind SK channels in a similar way as apamin (Ishii et al., 1997a), but, in contrast to apamin the inhibition of SK channels by DTC is readily reversible. Indeed, the $\mathrm{m} I_{\text {AHP }}$ component was reversibly blocked by DTC (Fig. 3C, insert). Mean inhibition by DTC had a concentration-response curve that was well described with a single Hill function and had an $\mathrm{IC}_{50}$ of $52 \mu \mathrm{M}$ and a Hill coefficient of $1.5\left(n=30\right.$; mean $\mathrm{IC}_{50}$ of DTC $=52.8 \pm 3.1 \mu \mathrm{M} ; n=16)($ Fig. $3 D)$, again consistent with the presence of a single type of SK channel. This $\mathrm{IC}_{50}$ is similar to that reported for SK3 channels in recombinant systems, which had an $\mathrm{IC}_{50}$ of $63 \mu \mathrm{M}$ (Ishii et al., 1997a). The biophysical and pharmacological analysis strongly suggested the presence of a single SK channel subtype, most likely SK3, in DA SN neurons.

\section{SK channels act as dynamic low-pass filters of pacemaker frequency in DA SN neurons}

The quantitative pharmacological results enabled us to study the physiological effects of defined inhibition and activation of SK channels in DA SN neurons. These experiments were performed under conditions of intact intracellular calcium handling with gramicidin-perforated patch recordings. Fast synaptic transmission was pharmacologically inhibited to ensure the functional isolation of the intrinsic pacemaker. DA SN neurons displayed spontaneous low-frequency pacemaker discharge in the range from $0.6-4.3 \mathrm{~Hz}$ (Fig. 4). The application of $80 \mu \mathrm{M}$ DTC, which inhibited $\sim 2 / 3(66 \%)$ of SK channels in DA SN neurons, was sufficient to induce an increase in the spontaneous pacemaker frequency (Fig. 4A). The fact that a partial inhibition of SK channels had functional consequences argues for a tight control of the pool of active SK channels in DA neurons. Higher DTC concentrations (1 mM) that completely blocked SK channels further accelerated the discharge frequency and depressed the AHPs (Fig. 4B,C). Furthermore, the activation of SK channels by $200 \mu \mathrm{M} 1-\mathrm{EBIO}$ decelerated the spontaneous discharge frequency and increased the AHP amplitude and duration (Fig. 4D). These data are consistent with previous results that indicated a role for SK channels in the control of the firing frequency of DA midbrain neurons (Shepard and Bunney, 1991; Ping and Shepard, 1996). However, heterogeneous responses to SK inhibition have been described for dopaminergic neurons, i.e., the application of apamin increased the frequency of firing in some DA neurons but had no effect on others. Also, some neurons became more irregular, whereas others switched to a burst mode in response to apamin (Shepard and Bunney, 1988, 1991; Gu et al., 1992; Shepard and Stump, 1999). Interestingly, the DTC-mediated increase and the 1-EBIO-mediated decrease of the spiking frequencies were itself depended on the pacemaker frequency in DA SN neurons (Fig. 4E). To also study frequencies above the observed range of spontaneous discharge, we injected different amplitudes of positive currents $(5-50 \mathrm{pA})$. At the low-frequency end of the spectrum of spontaneous discharge rates $(<2 \mathrm{~Hz})$, partial SK inhibition had a small but significant effect on discharge rates (relative change, $1.1 \pm 0.02 ; n=31 ; p<0.0001$ ). With increasing discharge rates, the relative effect of partial SK inhibition increased and saturated at frequencies $>6 \mathrm{~Hz}$ where partial SK inhibition induced an maximal increase in discharge rates of $50 \%$ $(1.5 \pm 0.1$ at $6-8 \mathrm{~Hz} ; n=7)$. As expected, complete SK inhibition by $1 \mathrm{mM}$ DTC also increased firing in a frequency-dependent manner $(1.7 \pm 0.1$ at $2-4 \mathrm{~Hz} ; n=10 ; 2.3 \pm 0.2$ at $4-6 \mathrm{~Hz} ; n=$ 5 ; data not shown). The effects of partial and complete SK inhibition were not significantly different in the lower frequency group of $0-2 \mathrm{~Hz}(1.2 \pm 0.1 ; n=8 ; p=0.08)$. Similar results were obtained by partial $(20 \mathrm{~nm})$ or complete $(300 \mathrm{~nm})$ inhibition of SK 

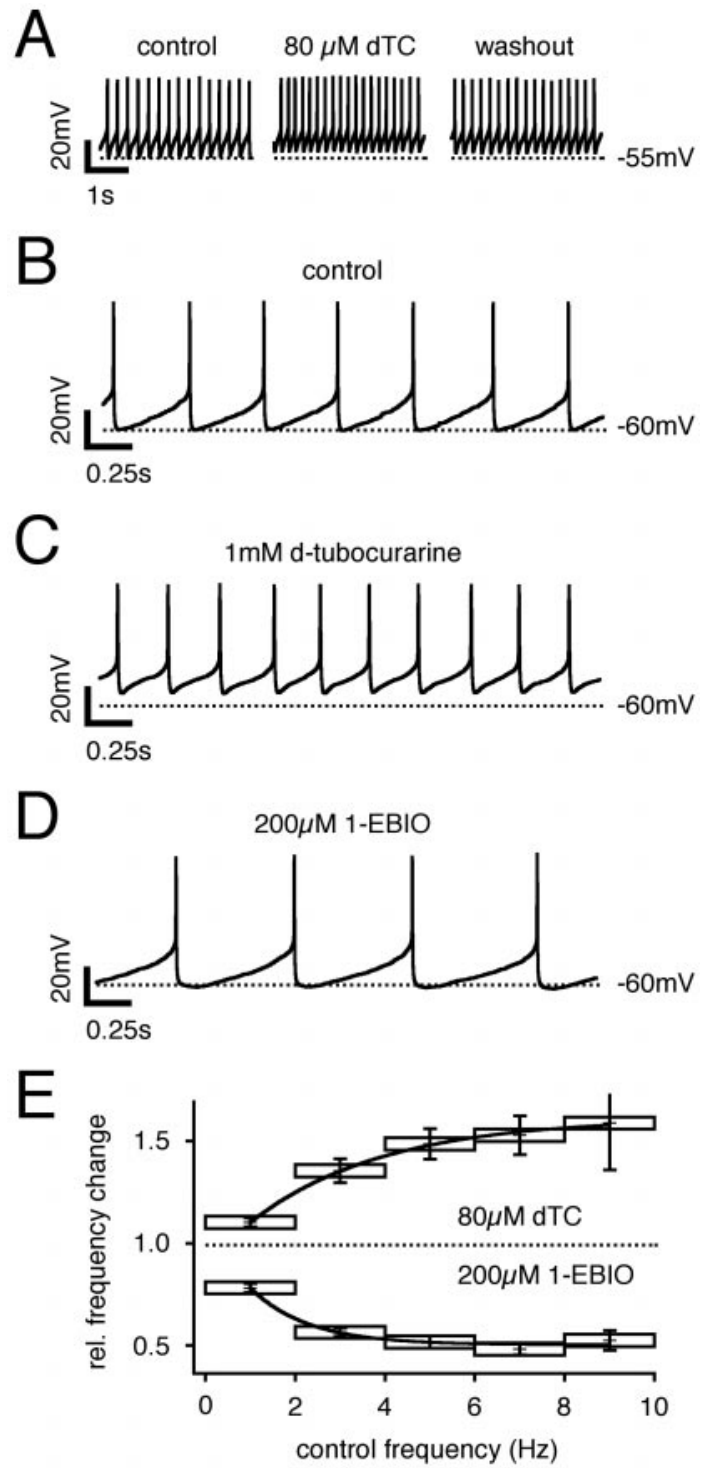

Figure 4. SK channels dynamically control pacemaker frequencies in DA SN neurons. $A-D$, Current-clamp recordings of SN DA neurons in the gramicidin-perforated patch configuration. $A$, Partial (2/3) inhibition of SK channels by $80 \mu \mathrm{M}$ DTC resulted in a reversible increase of spontaneous discharge (3.8-4.8 Hz). B, Control pacemaker frequency $(2.3 \mathrm{~Hz})$. Note that single spike AHPs peak at $-60 \mathrm{mV}$. C, A $1 \mathrm{~mm}$ concentration of DTC reduced AHP peak amplitudes and increased the spiking frequency to $3.3 \mathrm{~Hz}$ (relative change, 1.4). D, A $200 \mu \mathrm{M}$ concentration of 1-EBIO increased AHP peak amplitudes and duration and decreased the spiking frequency to $1.3 \mathrm{~Hz}$ (relative change, 0.5 ). Action potentials were truncated for clarity. $E$, Summary of experiments as in $A-D$. Control frequencies were combined in $2 \mathrm{sec}$ bins $(n=3-31)$ to compare the effect of $200 \mu \mathrm{M} 1$-EBIO, $80 \mu \mathrm{M}$ DTC. A broader frequency range $(>6 \mathrm{~Hz})$ was achieved by injecting positive current. Partial inhibition and activation of SK channels by $80 \mu \mathrm{M}$ DTC and $200 \mu \mathrm{M}$ 1-EBIO, respectively, altered the discharge rate in a frequency-dependent manner with increased efficiency at higher discharge rates.

channels by apamin (20 nM apamin: $1.2 \pm 0.1$ at $2-4 \mathrm{~Hz}, n=32$; $1.4 \pm 0.1$ at $4-6 \mathrm{~Hz}, n=3 ; 300 \mathrm{~nm}$ apamin: $1.5 \pm 0.1$ at $2-4 \mathrm{~Hz}$, $n=34 ; 1.7 \pm 0.3$ at $4-6 \mathrm{~Hz}, n=3$; data not shown). In accordance with the frequency dependence of SK inhibition, partial activation of SK channels with $200 \mu \mathrm{M}$ 1-EBIO also showed a similar frequency dependence. The effect of $200 \mu \mathrm{M}$ 1 -EBIO increased at higher discharge frequencies and was satu- rated at frequencies $>4 \mathrm{~Hz}$, reducing the discharge rate to $50 \%$ $(0.50 \pm 0.03$ at $6-8 \mathrm{~Hz} ; n=8)$. Higher 1 -EBIO concentrations (0.5-2 mM) led to tonic membrane hyperpolarizations that prevented pacemaker activity (data not shown). These results show that with increasing discharge frequencies the functional role of SK channels becomes more dominant in the control of excitability. It is reasonable to assume that this frequency dependence of SK channel recruitment is related to rising calcium concentrations during enhanced activity (Wilson and Callaway, 2000). As a consequence, the relative importance of SK channels in shaping firing increases with faster spiking frequencies. Thus, SK channels might act as low-pass filters that stabilize the frequency of the discharge and ensure lower firing rates. Sudden increases of spike rates are likely to recruit more SK channels to the active pool and counteract the initial acceleration by negative feedback.

\section{SK channels control pacemaker precision in DA SN neurons}

An additional function of SK channels in pacemaker control could be to enhance the precision of the intrinsic pacemaker mechanism, because SK channel activation might counteract the variability of individual interspike intervals. To quantify the role of SK channels in pacemaker precision, the distribution and variance of ISIs during continuous recording were analyzed (Figs. $5,6)$. These recordings were performed in the perforated-patch configuration under pharmacological inhibition of fast synaptic transmission. In accordance with previous studies (Grenhoff et al., 1988; Shepard and German, 1988) the DA SN pacemaker showed a high degree of precision, and the distribution of ISIs could be described with single Gaussian functions (Figs. 5A, 6A). The CV, measured by the SD of fitted Gaussian function normalized to the mean ISI, was only $\sim 10 \%$ of the mean ISI of SN DA neurons $(12.4 \pm 1.6 \% ; n=12)$. Partial inhibition of SK channels by $80 \mu \mathrm{M}$ DTC enhanced the variability of ISIs by $\sim 40 \%$ $(\mathrm{CV}, 17.5 \pm 1.8 \% ; n=12 ; p<0.001)$ (Fig. $5 B, D)$. This effect was more pronounced by complete inhibition of SK channels by $1 \mathrm{~mm}$ DTC, which subsequently increased the ISI variability by $140 \%$ compared with control conditions $(\mathrm{CV}, 30.0 \pm 2.9 \% ; n=10 ; p<$ 0.0001 ) (Fig. $5 C, D$ ). The DTC effect on precision was partially reversible after washout of the drug $(\mathrm{CV}, 15.6 \pm 2.4 \% ; n=3)$ (Fig. 5D). Similar results were obtained by application of apamin (Fig. 6). Already partial SK inhibition by $20 \mathrm{~nm}$ apamin reduced the precision of firing (CV control: $12.1 \pm 1.2 \%, n=11$; CV 20 nM apamin: $16.5 \pm 2.3 \%, n=9, p=0.02)$, which was further decreased by complete SK inhibition in $300 \mathrm{~nm}$ apamin (CV 300 nм apamin: $32.8 \pm 5.6 \%, n=11, p<0.005)$. These results demonstrate that the pool of active SK channels is intimately involved in the control of the precision and timing of the endogenous pacemaker in DA SN neurons.

\section{DA SN neurons express SK3 channels}

To assess the molecular composition of the SK channels that may exert this control over the pacemaker in identified DA SN neurons, we combined patch-clamp recordings with both qualitative single-cell RT-multiplex (m) PCR, as developed by Lambolez et al. (1992) and semiquantitative single-cell RT-PCR, as established by Tkatch et al. (1998, 2000). A single-cell RT-mPCR protocol was designed to simultaneously detect levels of the mRNAs of the SK channel subunits SK1, SK2, SK3, and SK4. In addition, the protocol probed for the expression of the marker genes TH for dopaminergic neurons and GAD67 for GABAergic neurons (Liss et al., 1999a). The sizes of each of the PCR 

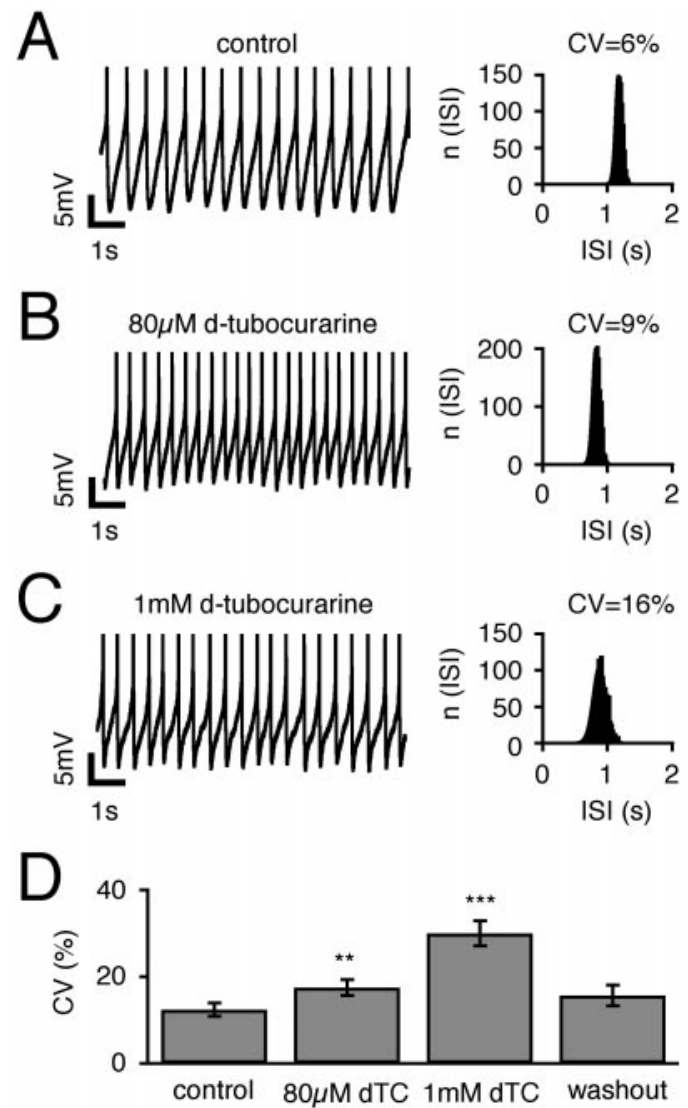

Figure 5. D-Tubocurarine-sensitive SK channels maintain high precision of the pacemaker in DA SN neurons. $A-C$, Current-clamp recordings of SN DA neurons in the gramicidin-perforated patch configuration during control and DTC application. Representative traces $(10 \mathrm{sec})$ are shown for each condition. Action potentials were truncated at $-30 \mathrm{mV}$, and mean peak AP amplitudes were $-29.1 \pm 0.1 \mathrm{mV}(n=50)$ for control, $-27.7 \pm$ $0.1 \mathrm{mV}(n=50)$ for $80 \mu \mathrm{M} \mathrm{DTC}$, and $-21.0 \pm 0.6 \mathrm{mV}(n=50)$ for $1 \mathrm{mM}$ DTC. ISI histograms for each condition are depicted in the right panels, respectively. ISI frequency distributions were described by single Gaussian functions, and the resulting coefficient of variation was calculated as a measure of pacemaker precision. $A$, Control $(\mathrm{CV}, 6 \%)$. B, Partial (2/3) inhibition of SK channels by $80 \mu \mathrm{M}$ DTC increased the spiking frequency and decreased spiking precision $(\mathrm{CV}, 9 \%)$. C, Complete block of SK channels (1 mM DTC) resulted in a further reduction of spiking precision $(\mathrm{CV}, 16 \%) . D$, Summary of experiments as in $A-C$. The mean CVs in control, $80 \mu \mathrm{M}$ DTC, $1 \mathrm{mM}$ DTC, and washout were $12.4 \pm 1.6 \%(n=12)$, $17.5 \pm 1.8 \%(n=12 ; p=0.001), 30.0 \pm 2.9 \%(n=10 ; p<0.0005)$, and $15.6 \pm 2.4 \%(n=3)$, respectively.

amplicons were predicted by their respective mRNA sequences. Figure $7 A$ shows that the six specific PCR products were detected from lung cDNA diluted to the picogram range. Consistent with previous findings (Kohler et al., 1996; Ishii et al., 1997b; Stocker and Pedarzani, 2000), mRNAs for SK1-SK3, but not SK4 channel subunits are expressed in brain, as well as TH and GAD67 (Fig. $7 B$ ). The single-cell RT-mPCR protocol was then used to analyze SK channel subunit expression in individual DA SN neurons. Because the genomic structures of the mouse SK1-SK4 genes were unknown at the time of primer design, single-cell mPCR amplifications were performed without previous reverse transcription to probe for possible amplification of genomic DNA from the harvested single nuclei. No PCR products were detectable from the cells tested in this way ( $n=5$; data not shown). Thus, our protocol was suited to study the genuine SK1-4 mRNA expression profiles of single neurons. Consistent with previous in
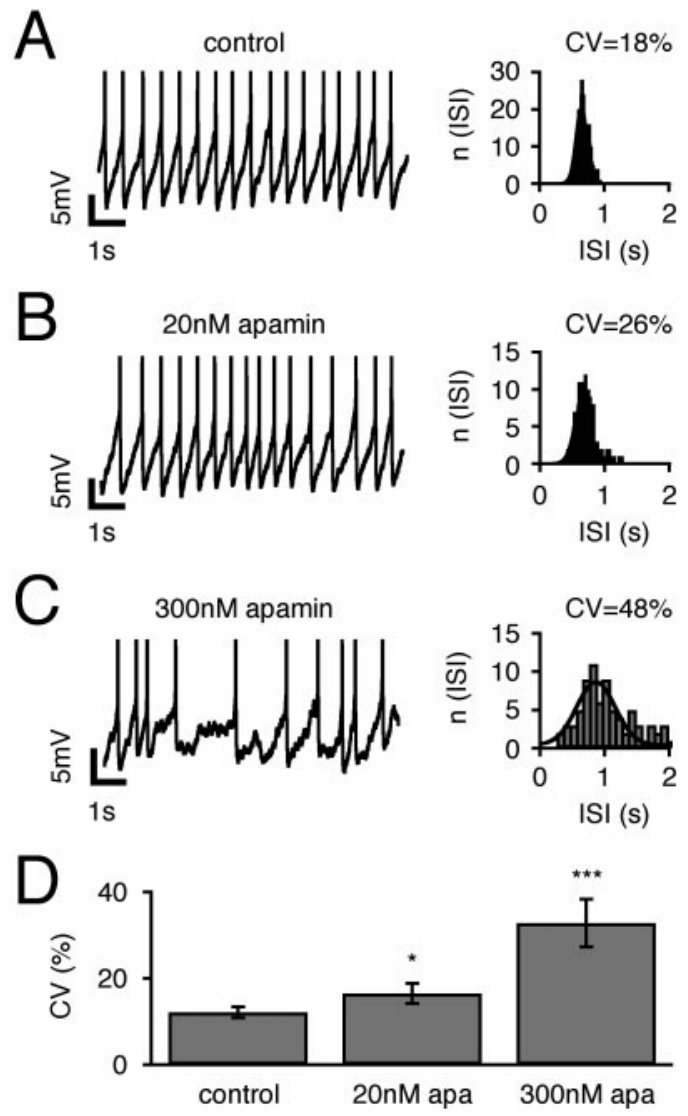

Figure 6. Selective inhibition of SK channels by apamin dramatically reduces pacemaker precision in DA SN neurons. $A-C$, Current-clamp recordings of SN DA neurons in the gramicidin-perforated patch configuration during control and apamin application. Representative traces (10 $\mathrm{sec})$ are shown for each condition. Action potentials were truncated at $-15 \mathrm{mV}$, and mean peak AP amplitudes were $-7.8 \pm 0.1 \mathrm{mV}(n=50)$ for control, $-6.7 \pm 0.2 \mathrm{mV}(n=50)$ for $20 \mathrm{nM}$ apamin, and $-5.8 \pm 0.2 \mathrm{mV}$ $(n=50)$ for $300 \mathrm{~nm}$ apamin. ISI histograms for each condition are depicted in the right panels, respectively. ISI frequency distributions were described by single Gaussian functions, and the resulting coefficient of variation was calculated as a measure of pacemaker precision. $A$, Control $(\mathrm{CV}, 18 \%)$. B, Partial inhibition of SK channels by $20 \mathrm{~nm}$ apamin decreased spiking precision $(\mathrm{CV}, 26 \%)$. C, Complete block of SK channels (300 nM apamin) resulted in a strong reduction of spiking precision $(\mathrm{CV}$, $48 \%$ ). $D$, Summary of experiments as in $A-C$. The mean CVs in control, $20 \mathrm{nM}$, and $300 \mathrm{nM}$ apamin were $12.1 \pm 1.2 \%(n=11), 16.5 \pm 2.3 \%(n=$ $9 ; p=0.02)$, and $32.8 \pm 5.6 \%(n=11 ; p<0.005)$, respectively.

situ hybridization studies that showed high SK3 mRNA expression in dopaminergic midbrain nuclei (Kohler et al., 1996; Stocker and Pedarzani, 2000), SK3 mRNA was detected in all THpositive neurons displaying medium $I_{\mathrm{AHP}} \mathrm{S}(n=19)$ (Fig. $\left.7 C, D\right)$. In contrast to SK3 mRNA, the expression of SK1 and/or SK2 mRNA was only detected in a minority of DA cells (Fig. 7D). Figure 7, $E$ and $F$, plots single-cell genotype-phenotype correlations for DA neurons comparing the expression of SK1-3 in a given neuron with the amplitude and decay time constant of the SK-mediated $\mathrm{m} I_{\mathrm{AHP}}$, determined in the same cell. Differential mRNA coexpression of SK1 and/or SK2 with the prominent SK3 mRNA was not correlated with a significantly different phenotype of the $\mathrm{m} I_{\mathrm{AHP}}$. In addition to these qualitative single-cell $\mathrm{mPCR}$ results, we used serial dilutions of single-cell cDNA pools to quantify the PCR detection limits of SK1, SK2, and SK3 mRNA in single DA neurons (Fig. 8). The frequency distribution of single-cell SK3 detection thresholds was well described with a 

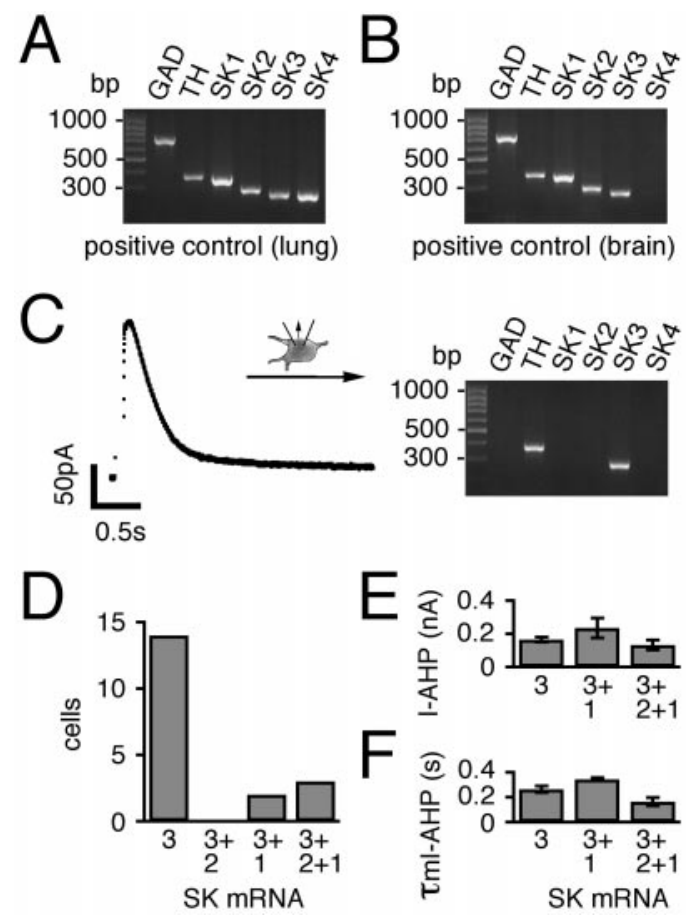

Figure 7. SK3 mRNA is the dominant SK mRNA species in single, identified SN DA neurons. $A, B$, PCR products of nested PCR reactions were resolved in separate lanes by gel electrophoresis gels in parallel with a 100 bp ladder as molecular weight marker. All SK channel subunit mRNAs as well GAD and TH mRNAs are expressed in mouse lung tissue (positive controls), and with the exception of SK4, all transcripts were also present in brain. The predicted sizes (in base pairs) of the PCR amplicons were 702 (GAD67), 377 (TH), 375 (SK1), 310 (SK2), 290 (SK3), and 285 (SK4). $C$, Single-cell RT-multiplex PCR experiment of a DA SN neuron: after eliciting the $I_{\mathrm{AHP}}$ current (left panel) (compare Fig. 1C), the cytoplasm was harvested for RT-mPCR analysis. The respective single-cell mRNA expression profile $\left(\mathrm{TH}^{+}, \mathrm{SK}^{+}\right)$was displayed by gel electrophoresis (right panel). $D$, Distribution of single-cell RT-mPCR expression profiles from SN DA $\left(\mathrm{TH}^{+}\right)$neurons with medium $I_{\mathrm{AHP}}$ s. $E, F$, Single-cell phenotype-genotype correlation between amplitude $(E)$ and kinetics $(F)$ of $I_{\mathrm{AHP}}$ and SK1-SK3 expression profiles in DA SN neurons. Codetection of SK1 and/or SK2 with the prominent SK3 was not correlated with a significantly different $I_{\mathrm{AHP}}$ phenotype.

single Gaussian function, indicating a mean SK3 detection threshold of $13 \pm 4 \%\left(2^{-2.9}\right)$ of the single-cell cDNA pools (Fig. $8 A, B$ ). Whereas SK3 was again detected in all cells with detection thresholds up to a 1:16 dilution, SK1 or SK2 mRNAs were in most cases not detected (SK1 6/9, SK2 4/6 cells) or only detected up to a 1:4 dilution in similar serial dilution single-cell RT-PCR experiments (Fig. $8 C, D$ ). These results indicate that SK3 mRNA is expressed with at least a fourfold higher abundance compared with SK1 or SK2 in single DA neurons. On the level of mRNA, SK3 is clearly the ubiquitous and dominant species in identified single DA SN neurons.

\section{Differential expression of SK3 protein is correlated with different $I_{\text {AHP }}$ amplitudes in DA midbrain neurons}

To study the expression of SK3 on the protein level in DA midbrain neurons, confocal immunohistochemistry was performed on mouse midbrain sections. Double labeling with SK3 antibodies was done in combination with $\mathrm{TH}$ antibodies to identify DA neurons. The low-power overview of a coronal midbrain section, shown in Figure 9, demonstrates that SK3 protein is prominently expressed in TH-positive, i.e., DA SN neurons,
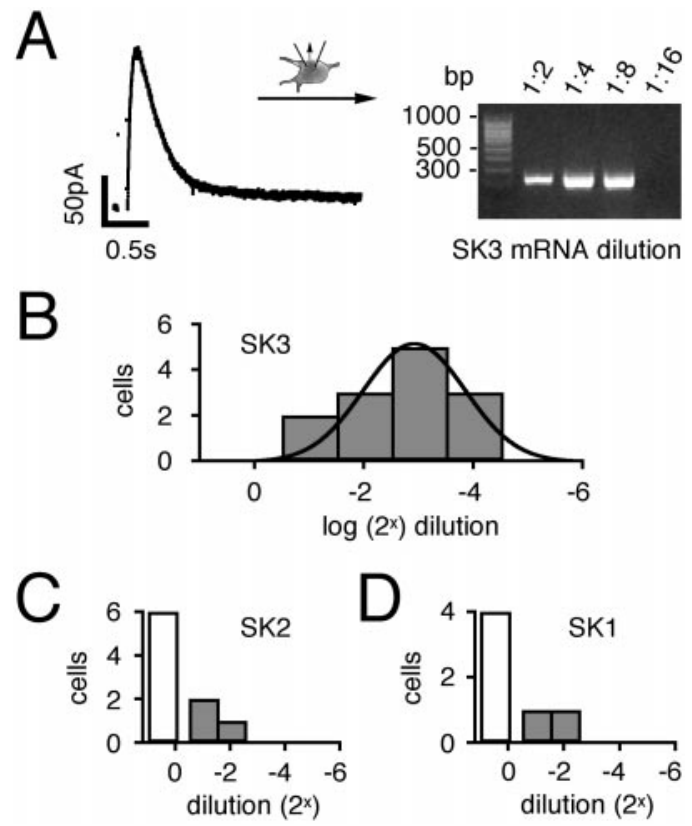

Figure 8. Semiquantitative single-cell RT-PCR demonstrates that SK3 mRNA is most abundant in SN DA neurons. $A$, Semiquantitative singlecell RT-PCR experiment of a DA SN neuron: after eliciting the $I_{\mathrm{AHP}}$ current (left panel) (compare Fig. 1C), the cytoplasm was harvested for RT. Serial dilutions of the single-cell cDNA pool were analyzed by nested PCR. Gel electrophoresis analysis (right panel) demonstrated SK3 detection in up to one-eighth of the respective single-cell cDNA pool. $B-D$, Frequency distribution of SK3 $(A)$, SK2 $(B)$, and SK1 $(C)$ detection thresholds in SN DA $\left(\mathrm{TH}^{+}\right)$neurons. Whereas SK1 and SK2 were not detected in most cases (white bars), the distribution of SK3 detection thresholds was well described with single Gaussian function, indicating a mean detection from $13 \pm 4 \%\left(2^{-2.9} ; n=13 ; B\right)$ of the single-cell cDNA pools.

which is consistent with our previous single-cell RT-PCR results. There is little SK3 immunoreactivity in TH-negative i.e., nondopaminergic midbrain neurons. However, the intensity of SK3 immunolabeling was not uniformly distributed in different DA subpopulations in the midbrain: whereas it was strong in the substantia nigra pars compacta-in particular the ventral tierthe SK3 immunosignal was weaker by comparison in the dorsal tier of the SN and the VTA (A10). To compare DA neurons in the SN and the VTA, high-resolution intensity maps of SK3 immunolabeling were generated and scanned with identical confocal settings (Fig. 10) (similar results in 10 independent experiments). This comparison not only revealed prominent SK3 signals decorating the somatodendritic membranes of DA neurons, but also showed that a stronger SK3 immunosignal was present in DA neurons in the substantia nigra pars compacta (Fig. 10, compare $B, F)$. To assess directly the functional relevance of the observed differences in SK3 protein expression, we combined electrophysiological recordings of $I_{\mathrm{AHP}} \mathrm{S}$ in neurobiotin-filled DA neurons with triple-labeling immunohistochemistry and semiquantitative analysis of the SK3 immunosignal in the recorded and reconstructed neurons (Fig. $11 A-F$ ). The absolute background levels were similar in VTA $(16.2 \pm 2.4 ; n=23)$ and SN $(17.9 \pm 1.4 ; n=49)$. To account for small background variances between different slices, absolute SK3 immunosignals (34.8 \pm 3.2 ; $n=44$ ) from individual neurons were normalized to an averaged SK3 background signal in the respective images (Fig. $11 F$, insert). Analysis of forty-four DA SN neurons revealed a significant 

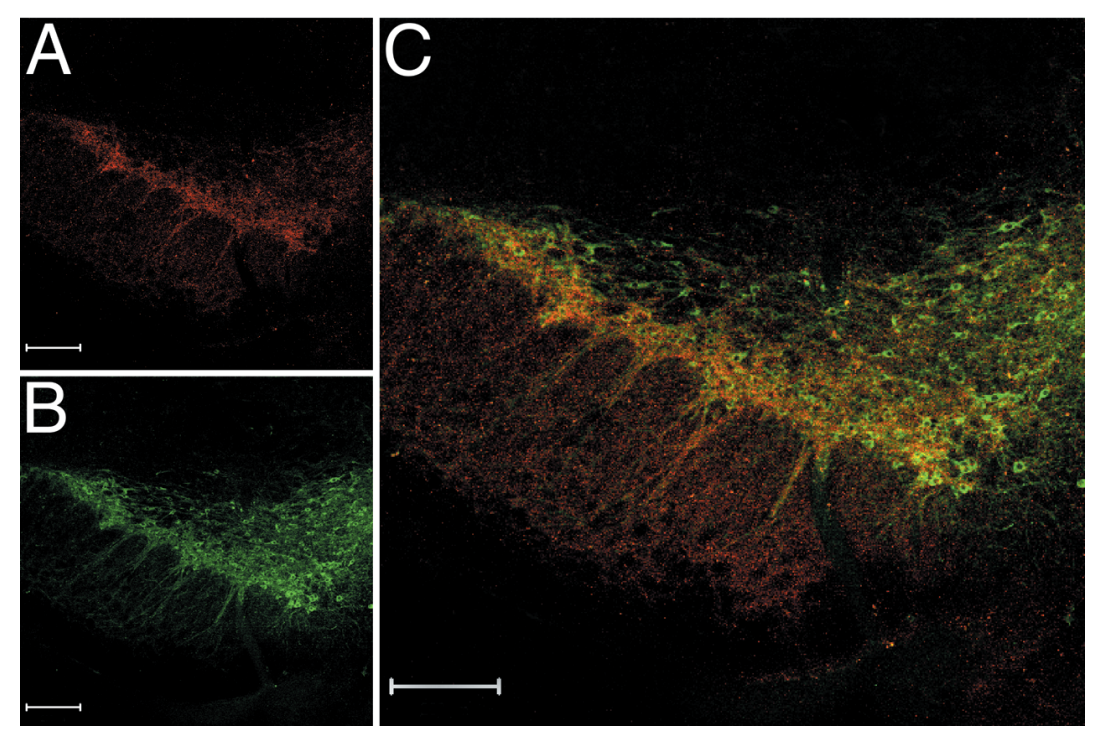

Figure 9. Double immunolabeling indicates prominent SK3 protein expression in dopaminergic midbrain neurons. $A$ shows a low-power overview of the distribution of SK3 immunoreactivity (red) in a coronal mouse midbrain section. Note prominent SK3 signals in the ventral tier of substantia nigra pars compacta (SNpc, A9), and weaker staining in the dorsal SNpc and the VTA (A10). $B$ shows the $\mathrm{TH}$ immunolabeling in the same section revealing the well described distribution of TH-positive, i.e., dopaminergic, midbrain neurons in the A9 and A10 nuclei. The superimposed image shown in $C$ indicates cellular colocalization of SK3 and TH protein within the SNpc and to a lesser degree in the VTA at higher power. Scale bars, $200 \mu \mathrm{m}$.

correlation between $I_{\mathrm{AHP}}$ amplitudes and SK3 immunosignal intensities $(r=0.42 ; p<0.005)$. These results demonstrate that the expression of SK3 subunits is an important molecular determinant for the number of functional SK channels in DA neurons. As shown in Figures 9 and 10, DA VTA neurons express less SK3 protein. To assess the functional significance of this finding, we also combined the recording of $I_{\mathrm{AHP}} \mathrm{S}$ in DA VTA neurons with triple-labeling immunohistochemistry (Fig. 12A-F). Consistent with lower SK3 expression, DA VTA neurons displayed smaller $I_{\mathrm{AHP}}$. The $I_{\mathrm{AHP}} \mathrm{S}$ in DA VTA neurons consisted of only one component that decayed with a mean time constants of $619 \pm 30$ msec ( $n=12$; data not shown). However, the pharmacological properties of the $I_{\mathrm{AHP}} \mathrm{S}$ in DA VTA neurons-i.e., activation by 2 mM 1-EBIO (1.9 \pm 0.1-fold; $n=16)$ (Fig. 12G) and partial inhibition of the 1-EBIO-enhanced $I_{\mathrm{AHP}}$, by $80 \mu \mathrm{M}$ DTC (40 \pm $4 \% ; n=9)($ Fig. $12 H)$-were similar compared with those of the $\mathrm{m} I_{\mathrm{AHP}}$ in DA SN neurons. In addition, the $I_{\mathrm{AHP}} \mathrm{S}$ in DA VTA neurons were completely inhibited by 1 mM DTC $(n=3)$, and the removal of extracellular calcium reduced the $I_{\mathrm{AHP}}$ to $14 \pm 9 \%$ $(n=5)$. Quantitative analysis of 12 recorded, filled, and immunocytochemically analyzed DA VTA neurons clearly demonstrated that SK3 immunoreactivity was significantly smaller in VTA (20.1 \pm 2.9$)$ compared with DA SN neurons (3.7-fold; VTA, $1.23 \pm 0.04, n=12$; SN, $1.85 \pm 0.05, n=44, p<0.0001)$ (Fig. 12I). Interestingly, a similar difference has been reported between SN and VTA using quantitative apamin autoradiography (Mourre et al., 1984). In accordance with the quantified differences in SK3 protein expression, DA VTA neurons possessed fourfold smaller AHP currents (VTA, $25 \pm 1 \mathrm{pA}, n=12$; $\mathrm{SN}, 111 \pm 7 \mathrm{pA}, n=44, p<0.0001)$ (Fig. 12J). These results give clear evidence that differential SK3 expression in different DA subpopulations is closely linked to functionally relevant differences in calcium-sensitive $I_{\mathrm{AHP}}$ currents.

\section{SK3 channels do not control the discharge activity of DA VTA neurons}

To address the functional significance of the considerably smaller pool of SK3 channels in identified DA neurons of the VTA, we combined apamin application during perforated patch experiments with subsequent cell filling to confirm the dopaminergic identity of the recorded VTA neurons by double neurobiotin and TH immunohistochemistry (Fig. 13A-C). DA VTA neurons were spontaneously active with a higher mean rate of $2.9 \pm 0.4 \mathrm{~Hz}(n=$ 9) compared with SN DA neurons. Already under control conditions, DA VTA neurons discharged highly irregular compared with SN DA neurons, as evident from the large CV (Fig. 13A). Complete inhibition of SK3 channels by $300 \mathrm{~nm}$ apamin had little effect on this irregular pattern of discharge (Fig. 13B). As shown in Figure $13 D$, complete and specific SK inhibition had no significant effect on pacemaker activity in identified DA VTA neurons (CV control: $93.8 \pm 17.4 \%$; CV $300 \mathrm{~nm}$ apamin: $105.6 \pm 16.0 \%$, $n=8)$. Furthermore, neither complete inhibition of SK channels by $1 \mathrm{~mm}$ D-tubocurarine ( $n=4$; data not shown) nor activation of SK channels by $200 \mu \mathrm{M} 1$-EBIO ( $n=3$; data not shown) had significant effects on the spontaneous discharge rates of DA VTA neurons. Thus, in contrast to DA SN neurons, SK channels in DA VTA neurons were not involved in the control of the pacemaker frequency and precision.

The combination of electrophysiological recordings with cell filling and immunohistochemistry enabled us to provide a topography of differential expression and function of SK3 channels in dopaminergic midbrain neurons (Fig. 14). The positions of recorded and reconstructed DA neurons were mapped according to their ventrodorsal and mediolateral coordinates. Each symbol represents a single neuron, and the symbol size corresponds to the functional parameter determined for this particular cell. Figure $14 A$ plots the spatial distribution of SK-mediated $I_{\mathrm{AHP}}$ amplitudes. It is evident that DA VTA neurons display significantly smaller $I_{\mathrm{AHP}} \mathrm{S}$ compared with the majority of SN DA neurons, which show a considerable variability of recorded $I_{\mathrm{AHP}}$ currents. As we have shown, SK3 expression is clearly related to the degree of pacemaker precision illustrated in Figure $14 B$ by the topography of pacemaker variances $(\mathrm{CV})$, which are significantly larger (7.6-fold) in DA VTA compared with DA SN neurons (CV SN: $12.3 \pm 0.1 \%, n=17$; CV VTA: $93.8 \pm 17.4$, $n=8$ ) (Fig. 14B,D). Finally, the functional impact of complete inhibition (300 nM apamin) of SK3 channels expressed as the relative change of pacemaker variance (CV) was mapped. Whereas the precision of firing in SN DA neurons is severely affected, no significant change is induced by complete SK3 inhibition in DA VTA neurons (relative CV change SN: $2.9 \pm 0.4$, $n=10$; relative CV change VTA: $1.2 \pm 0.1 ; n=8$ ) (Fig. $14 C, E$ ). In summary, our data show that SK3 channels are differentially 

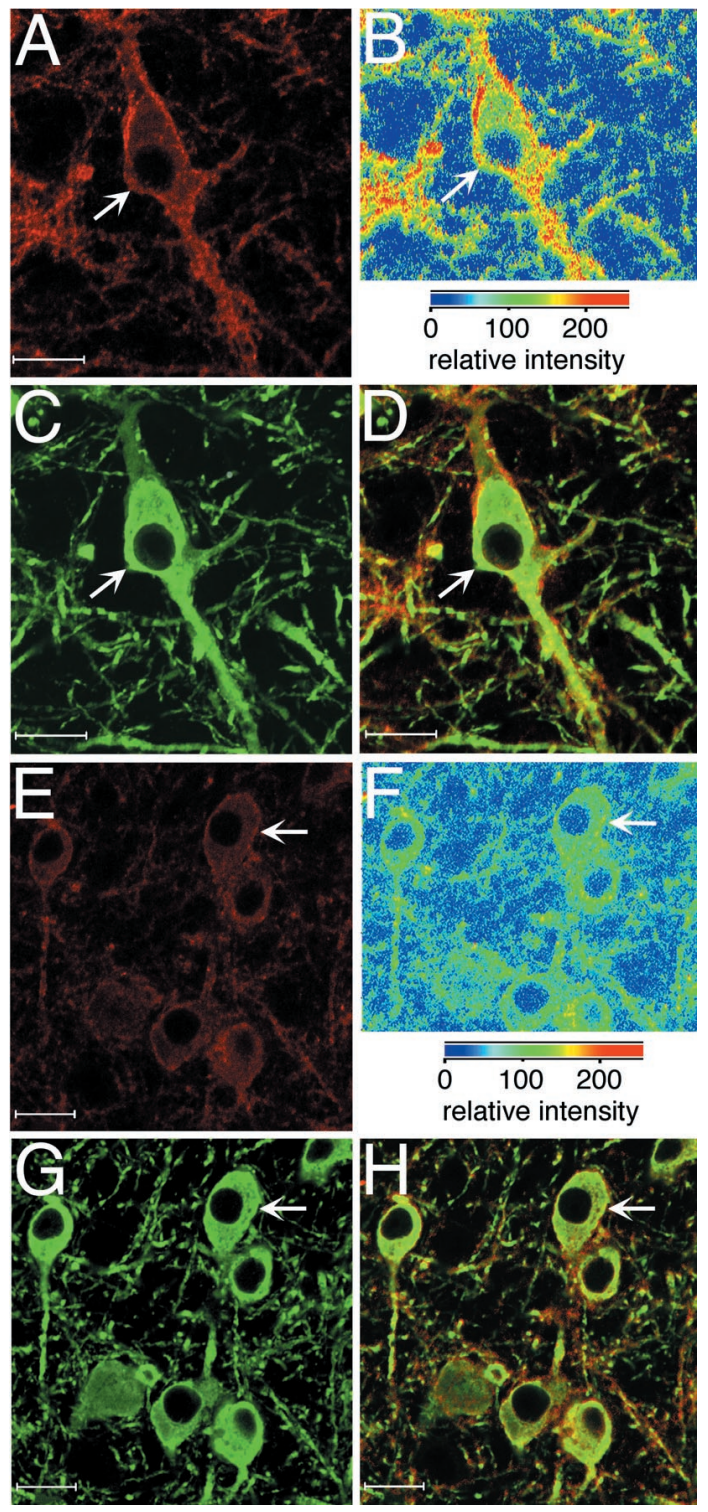

Figure 10. Differential SK3 protein expression in dopaminergic SN and VTA neurons. $A-D$, Double immunolabeling of SK3 (red, $A$; pseudocolorcoded SK3 intensity map, $B$ ) and TH (green, $C$; SK3 + TH overlay, $D$ ) of an SN neuron (arrow). Note that SK3 immunolabeling is most intense along the somatodendritic membrane of the DA SN neuron. SK3 protein is also present on TH-positive neuropil. $E-H$, Double immunolabeling of SK3 (red, E; pseudocolor-coded SK3 intensity map, $F$ ) and TH ( green, $G$; SK3 + TH overlay, $H$ ) of VTA neurons. Scanned with identical confocal settings for direct comparison of SK3 immunosignals in SN and VTA neurons, note that SK3 immunolabeling also labels somatodendritic membranes of VTA DA neurons but is considerably weaker compared with that in SN DA neurons. Scale bars, $20 \mu \mathrm{m}$.

expressed and are either coupled or uncoupled to the intrinsic pacemaker in different DA midbrain population.

\section{DISCUSSION}

\section{Molecular identity of SK channels in DA SN neurons}

Based on the combined results presented in this work (1) the homogeneous biophysical properties of calcium-sensitive AHP currents, (2) quantitative pharmacology, (3) multiplex and semiquantitative single-cell RT-PCR, and (4) semiquantitative multilabeling immunohistochemistry of recorded DA neurons, we con-

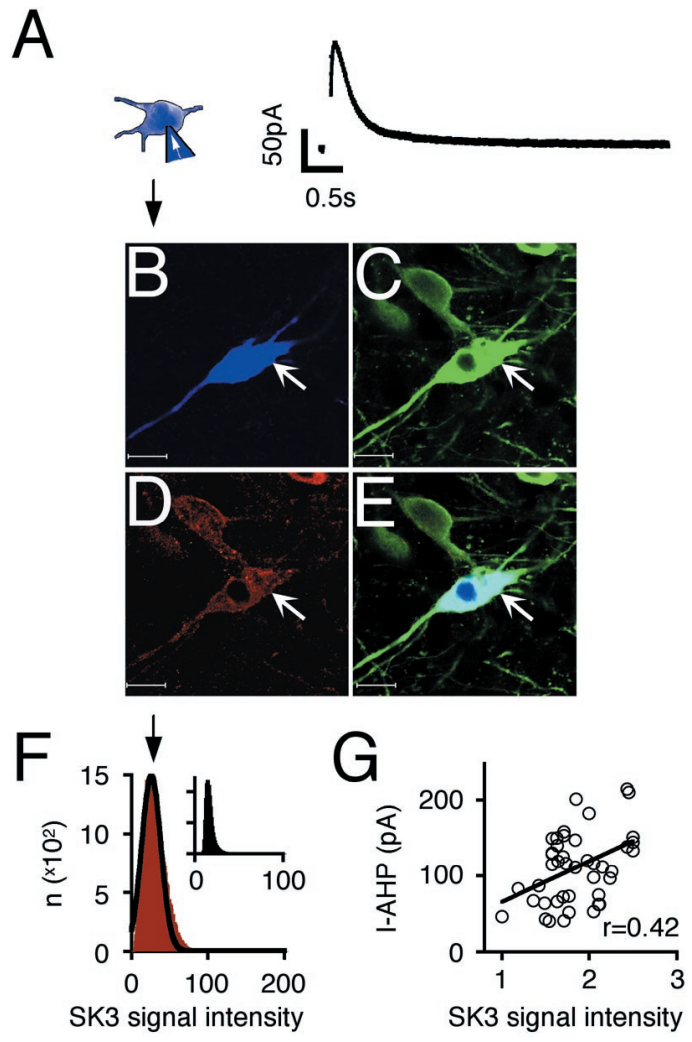

Figure 11. $I_{\mathrm{AHP}}$ amplitudes correlate with the intensity of SK3 immunolabeling in single DA SN neurons. $A, I_{\mathrm{AHP}}$ current was elicited in wholecell recording of an SN DA neuron that was filled with $0.2 \%$ neurobiotin for identification during subsequent quantitative confocal microscopy $(B-F)$. Triple immunolabeling of recorded SN DA neuron of neurobiotin (blue, $B$ ), TH (green, $C$ ), and SK3 (red, $D$; neurobiotin $+\mathrm{TH}+\mathrm{SK} 3$ overlay, $E)$. $F$, Semiquantitative analysis of the SK3 immunolabeling intensity distribution of the recorded SN DA neuron (arrow). A Gaussian function was fitted to the intensity distribution to determine the mean SK3 intensity level of the respective neuron (arrow; $26 \pm 0.02$ ). The SK3 background signal intensity was also well described by a Gaussian function (mean, $14 \pm 0.004$; inset). Scale bars, $20 \mu \mathrm{m}$. $G$, Single-cell correlations between $I_{\mathrm{AHP}}$ current amplitudes and SK3 immunolabeling intensities (normalized to fitted SK3 noise levels) as shown in $A-F$. The line indicates linear regression with a correlation coefficient of $r=0.42(n=$ $44 ; p<0.005)$.

clude that DA SN neurons express a single molecular type of SK channel that is most likely composed of SK3 subunits. In single DA SN neurons, SK3 mRNA is ubiquitously and dominantly expressed compared with SK1 and SK2 mRNAs. Intense SK3 immunoreactivity is localized at TH-positive i.e., DA neurons in the midbrain. Moreover, the quantified intensity distributions of SK3 immunoreactivity were correlated with the respective $I_{\mathrm{AHP}}$ amplitudes in identified DA SN neurons. This strongly suggests that SK3 expression is the key factor controlling the number of active SK channels in DA neurons. Although we cannot rule out a minor contribution to native SK channels by other SK subunits, the single-cell phenotype-genotype correlations did not provide evidence that distinct functional properties of native SK currents were associated with the detection or nondetection of SK1 or SK2 mRNA in DA SN neurons.

\section{SK3 channels mediate the calcium-sensitive $I_{\mathrm{AHP}}$ in DA SN neurons}

In accordance with our molecular studies, the hybrid pulse protocol elicited robust calcium-sensitive $I_{\mathrm{AHP}} \mathrm{S}$ in DA SN neurons 
A

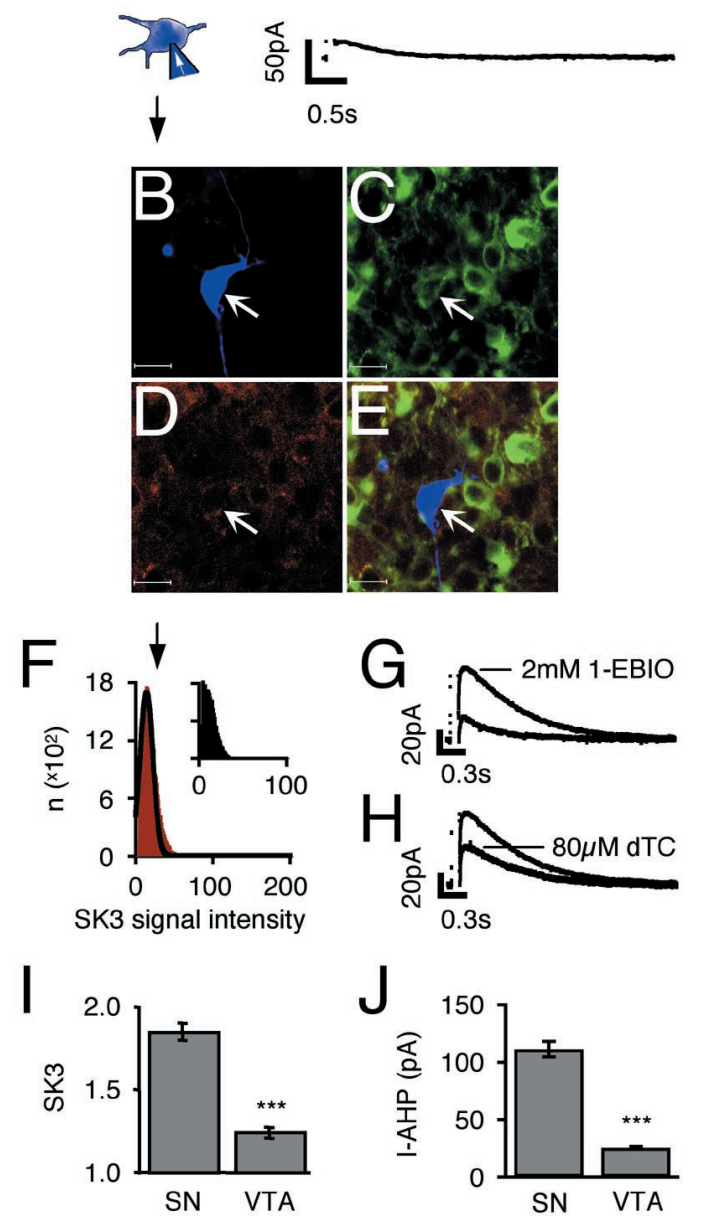

Figure 12. VTA DA neurons express smaller $I_{\mathrm{AHP}}$ currents and lower SK3 immunolabeling compared with SN DA cells. $A$, Small $I_{\mathrm{AHP}}$ was elicited in whole-cell recording of a VTA DA neuron that was filled with $0.2 \%$ neurobiotin for identification during subsequent quantitative confocal microscopy $(B-F)$. Triple immunolabeling of recorded VTA DA neuron of neurobiotin (blue, $B$ ), TH (green, $C$ ), and SK3 (red, $D$; neurobiotin $+\mathrm{TH}+\mathrm{SK} 3$ overlay, $E$ ). Scale bars, $20 \mu \mathrm{m}$. $F$, Semiquantitative analysis of the SK3 immunolabeling intensity distribution of the recorded SN DA neuron (arrow). A Gaussian function was fitted to the intensity distribution to determine the mean SK3 intensity level of the respective neuron (mean, $11 \pm 0.01$ ). The SK3 background signal intensity was also well described by a Gaussian function (mean, $9 \pm 0.08$; inset). $G$, $H$, Small $I_{\mathrm{AHP}}$ currents in VTA DA neurons show similar sensitivity to 1-EBIO $(1.9 \pm 0.1$-fold potentiation; $n=16)$ and DTC sensitivity (inhibition by $40 \pm 4 \% ; n=9$ ) but slower kinetics compared with those in DA SN neurons. $I$, Normalized SK3 immunolabeling intensities of recorded and reconstructed SN DA neurons $(1.85 \pm 0.05 ; n=44)$ were 3.7 -fold higher compared with those of VTA DA neurons $(1.23 \pm 0.04 ; n=12 ; p<$ $0.0005)$. $J$, Similar to SK3 immunolabeling intensities, $I_{\mathrm{AHP}}$ amplitudes of recorded and reconstructed SN DA neurons $(111 \pm 7 \mathrm{pA} ; 91 \pm 7 \%$ $\mathrm{m} I_{\mathrm{AHP}} \mathrm{s} ; n=44$ ) were 4.0 -fold larger compared with those of VTA DA neurons $(25 \pm 1 \mathrm{pA} ; n=12 ; p<0.0005)$.

with homogenous biophysical and pharmacological properties. The medium $I_{\mathrm{AHP}}$ reached its peak $\sim 50 \mathrm{msec}$ after the end of the depolarizing pulse and decayed with time constants in the range of 100-200 msec, which is similar to apamin-sensitive $I_{\mathrm{AHP}}$ currents in other peripheral or central neurons (Kirkpatrick and Bourque, 1996; Sah, 1996; Stocker et al., 1999). The kinetics of the SK3-mediated current are in between the much faster coupling of SK channels to their calcium source in outer hair cells
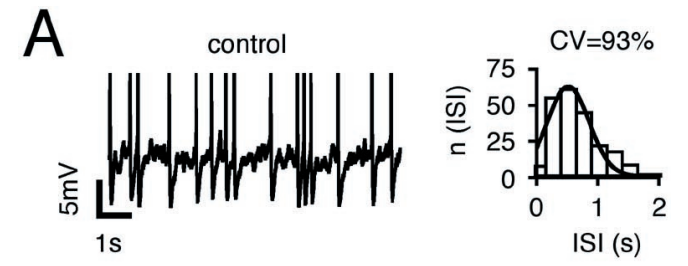

B

$300 n M$ apamin
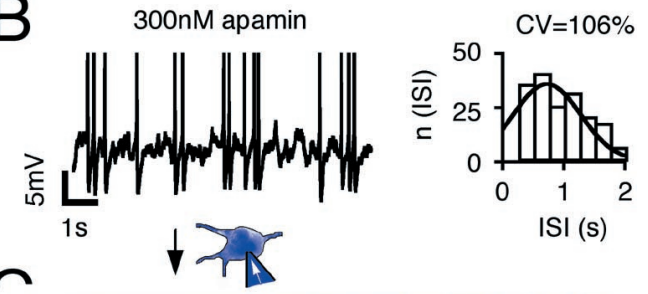

C

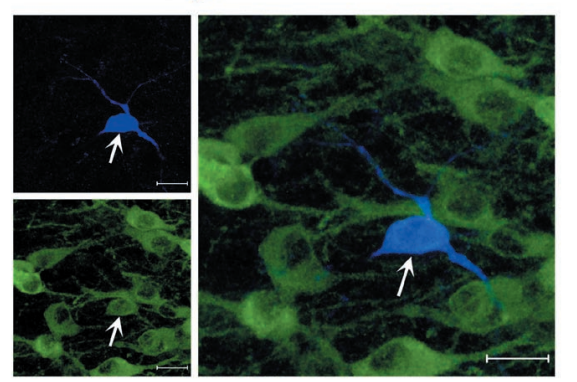

$D$

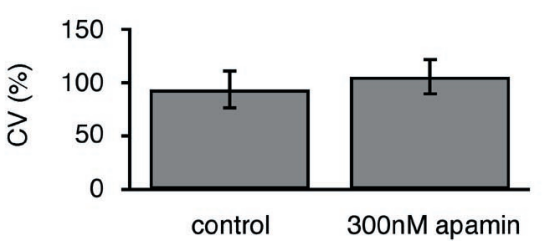

Figure 13. Identified VTA DA neurons display apamin-insensitive, lowprecision firing compared with SN DA neurons. Current-clamp recordings of an immunohistochemically identified VTA DA neuron in the gramicidin-perforated patch configuration during control $(A)$ and application of $300 \mathrm{~nm}$ apamin $(B)$. Representative traces $(10 \mathrm{sec})$ are shown in the left panels. Action potentials were truncated at $-15 \mathrm{mV}$, and mean peak AP amplitudes were $-12.3 \pm 0.1 \mathrm{mV}(n=50)$ for control and $-6.3 \pm 0.3 \mathrm{mV}(n=50)$ for $300 \mathrm{nM}$ apamin. ISI histograms for each condition are depicted in the right panels, respectively. ISI frequency distributions were described by single Gaussian functions, and the resulting coefficient of variation was calculated as a measure of pacemaker precision. $A$, VTA DA neurons showed low pacemaker precision during control condition (CV, 93\%) compared with SN DA neurons (Figs. 5, 6). $B$, Pacemaker precision and AHPs were not significantly affected by complete inhibition of SK channels (300 nM apamin; CV, 106\%). $C$, Identification and immunolabeling of the same neuron shown in $A$ and $B$. After the perforated-patch recording, the recording was converted to standard whole-cell, and the cell was filled with $0.2 \%$ neurobiotin. Subsequent double immunolabeling identified (neurobiotin, blue) and confirmed the recorded cell as a dopaminergic VTA neuron $(\mathrm{TH}$, green; overlay in right panel). Scale bars, $20 \mu \mathrm{m}$. D, Summary of experiments as in $A-C$. The mean $C$ Vs in control and $300 \mathrm{~nm}$ apamin were $93.8 \pm 17.4 \%$ $(n=8)$ and $105.6 \pm 16.0 \%(n=8 ; p=0.3)$.

(Oliver et al., 2000) and the slower activation of these channels by metabotropic glutamate receptors in DA neurons (Fiorillo and Williams, 1998). The monoexponential nature of the SK decay kinetics is consistent with both cytosolic calcium buffers and calcium efflux determining the decrease of submembrane calcium concentrations (Berridge, 1998; Wilson and Callaway, 2000). Our 1-EBIO experiments demonstrated that SK channels are not saturated by calcium during the hybrid protocol or physiological 

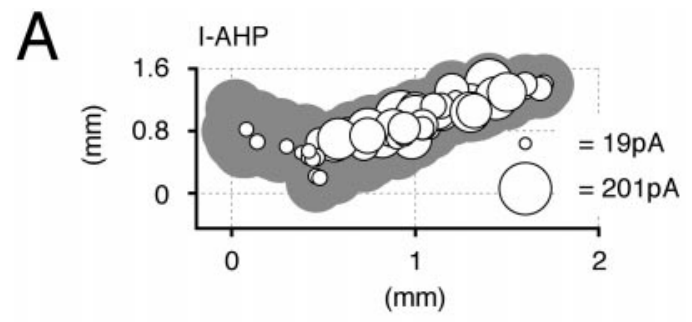

B

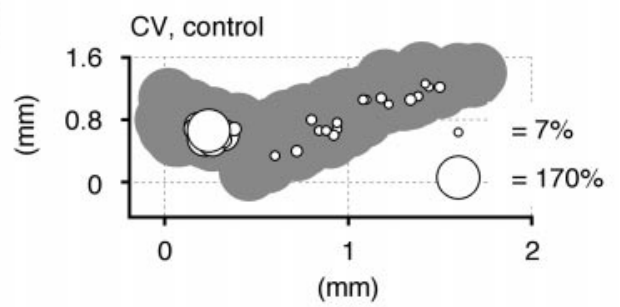

C

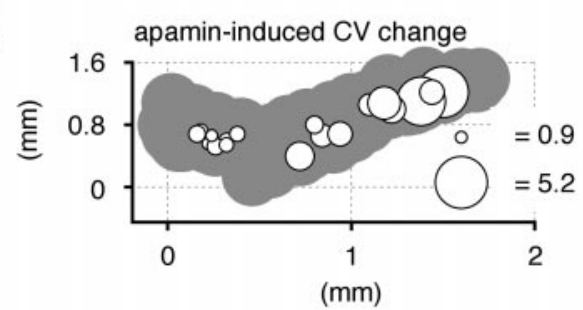

$\mathrm{D}$

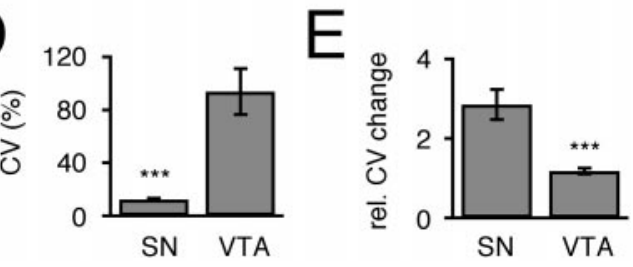

Figure 14. The topography of differential expression and function of SK3 channels in dopaminergic midbrain neurons. $A-C$, Spatial distribution of DA neurons in representative coronal midbrain slices (dorsal, up; medial, left). Each symbol represents a recorded, filled, and immunohistochemically identified DA neuron. $A, I_{\mathrm{AHP}}$ amplitudes of VTA and SN DA neurons. Symbol sizes corresponds to $I_{\mathrm{AHP}}$ amplitudes. VTA DA neurons display smaller $I_{\mathrm{AHP}} \mathrm{S}$. $B$, Pacemaker precision of VTA and SN DA neurons. Symbol sizes represent CV values (Figs. 5, 6, and 13). SN DA neurons display low $\mathrm{CV}$ values (high pacemaker precision). $C$, Effect of selective SK inhibition (300 nM apamin) on pacemaker precision of VTA and SN DA neurons. Symbol sizes represent apamin-induced changes of CV values. Pacemaker precisions of VTA DA neurons were less affected by SK inhibition. $D, E$, Summary of experiments in $B$ and $C$. Under control conditions, the mean CV of SN DA neurons $(12.4 \pm 0.9 \%$; $n=17)$ was significantly smaller compared with VTA DA neurons $(93.8 \pm 17.4 \% ; n=8 ; p<0.0005)$. E. Application of $300 \mathrm{~nm}$ apamin increased $\mathrm{CV}$ values approximately threefold in SN DA neurons $(2.9 \pm$ $0.4 ; n=10 ; p<0.005)$ but had no significant effects on firing of VTA DA cells $(1.2 \pm 0.1 ; n=8)$.

pacemaker activity, which is consistent with a recent calcium imaging study (Wilson and Callaway, 2000).

\section{SK3 channels act as dynamic frequency filters and precision devices in DA SN neurons}

The data presented here demonstrate that SK3 channels tightly control the pacemaker frequency in DA SN neurons. Importantly, this control is itself frequency dependent and more effective at higher discharge rates. The frequency range, in which SK channels exerted their dynamic control of pacemaking, was similar to the frequency range of spontaneous firing of DA SN neurons, emphasizing the physiological relevance of the dynamic frequency control by SK3. The range of frequency control by SK3 channels might explain previous observations that apamin increased firing rates in some but not all DA SN neurons (Shepard and Bunney, 1988, 1991; Gu et al., 1992; Shepard and Stump, 1999). Mechanistically, frequency-dependent accumulation of the intracellular calcium concentration that "represents an index of the recent spiking history" (Koch, 1999) might recruit more SK channels into the active pool to subsequently delay the pacemaker and thus to normalize discharge. The dynamic coupling of SK channels to pacemaker rates provides a negative feedback mechanism that is expected to decrease the interspike variability and thus enhance the precision of rhythmic single spike activity. Indeed, our results give direct evidence that SK3 channels are major players in enabling DA SN neurons to fire with a very low coefficient of variation. In contrast to previous studies (Shepard and Bunney, 1988; Gu et al., 1992), we have not routinely observed apamin-induced bursting in our perforated-patch study. This discrepancy might be attributable to differences in experimental temperature, age of the animals, and inhibition of tonic synaptic input.

\section{Differential expression and functional uncoupling of SK3 channels in DA VTA neurons}

The semiquantitative immunohistochemical and electrophysiological results provide clear evidence that SK3 channels are differentially expressed in distinct DA midbrain subpopulations. Compared with those in the VTA, DA neurons in the substantia nigra showed significantly higher SK3 protein expression and larger calcium-sensitive $I_{\mathrm{AHP}} \mathrm{S}$. Supporting the correlation between SK3 immunolabeling and $I_{\mathrm{AHP}}$ amplitudes, the differences between SN and VTA DA neurons were very similar (3.7-fold for SK3 protein and 4.0-fold for $\left.I_{\mathrm{AHP}} \mathrm{s}\right)$. This provides strong evidence that differential expression of SK3 channels is the dominant molecular mechanism used to control the functional pool of apamin-sensitive $\mathrm{K}^{+}$channels in DA midbrain neurons. The slower kinetics of the 1 -EBIO and DTC-sensitive $I_{\mathrm{AHP}} \mathrm{S}$ in DA VTA neurons might be linked to the differential expression of calcium-binding proteins in different DA midbrain subpopulations (Nemoto et al., 1999; Gonzalez-Hernandez and Rodriguez, 2000). In contrast to DA SN neurons, we found no evidence to suggest that the SK3 channels in DA VTA neurons are functionally coupled to the intrinsic pacemaker. Accordingly, DA VTA neurons fired in a irregular mode, irrespective of inhibition or activation of SK3 channels. These differences in SK3 channel expression between VTA and SN DA neurons constitute a candidate mechanism to explain the in vivo differences in pacemaker precision observed in these two DA subpopulations (Grenhoff et al., 1988). This mechanism might also, in part, be responsible for the described differences in pacemaker-burst transition between DA subpopulations (Li et al., 1996; Overton and Clark, 1997). It is well documented that inhibition of SK channels induces burst firing and facilitates NMDA-mediated burst firing in subpopulations of DA midbrain neurons (Shepard and Bunney, 1988, 1991; Gu et al., 1992; Seutin et al., 1993; Ping and Shepard, 1996). In addition, in vivo a higher percentage of DA VTA neurons display burst firing, compared with DA SN neurons (Grenhoff et al., 1988). If SK3 channels do not control the intrinsic pacemaker in DA VTA neurons, then what is their function in these neurons? There is good evidence that extrinsic, synaptic mechanisms activate SK channels in DA VTA neurons via metabotropic glutamate receptors (Fiorillo and Williams, 1998). Thus, differential 
expression and coupling of SK channels could serve different neurocomputational roles in either synaptic integration or control of intrinsic oscillations. Finally, our study on 2-week-old animals does not rule out the existence of other subpopulations of DA neurons in the VTA that display different firing pattern as reported here (Mueller and Brodie, 1989). DA populations might be plastic and change during development and aging. Indeed, there is controversy about the number and properties of functionally distinct DA populations in the VTA (Chiodo et al., 1984; Gariano et al., 1989). The localization of the DA population described here in the medial VTA and their lower firing precision that might correspond to a high bursting rate in vivo might suggest that their axons project predominantly to prefrontal target areas (Chiodo et al., 1984).

\section{Functional implications of altered SK3 channel expression in DA neurons for schizophrenia}

Our results provide a framework to study further the functional consequences of disease-related changes of SK3 expression in DA neurons. Altered activity of DA neurons are believed to be central in the pathophysiology of schizophrenia and the most effective antipsychotic treatment targets the DA system (Verhoeff, 1999; Svensson, 2000). Genetic studies have highlighted $\mathrm{KCNN} 3$, the gene that encodes for SK3 channels, as a candidate gene for schizophrenia (Chandy et al., 1998; Gargus et al., 1998; Antonarakis et al., 1999; Austin et al., 1999; Bonnet-Brilhault et al., 1999). The gene KCNN3 harbors unstable trinucleotide repeats in its coding region, and longer CAG repeats were overrepresented in some but not all studies in patients with schizophrenia. Thus, it has been suggested that expression of SK3 proteins with longer glutamine stretches might increase the susceptibility of individuals to schizophrenia (Gargus et al., 1998; Vincent et al., 2000). Based on analogies of other proteins harboring CAG repeats, it has been proposed that longer glutamine stretches might stabilize and thereby enhance SK3 function (Gargus et al., 1998). In context of our data, SK3 overexpression might be particularly effective in VTA DA neurons, where it could lead to the pathological expression of an SN-like, highly regular pacemaker phenotype. Consistent with this scenario, electrophysiological recordings from DA VTA neurons in animal models of schizophrenia have shown a marked discharge regularization (Svensson, 2000).

\section{REFERENCES}

Akaike N (1996) Gramicidin perforated patch recording and intracellular chloride activity in excitable cells. Prog Biophys Mol Biol 65:251-264.

Antonarakis SE, Blouin JL, Lasseter VK, Gehrig, C, Radhakrishna, U, Nestadt, G, Housman DE, Kazazian HH, Kalman, K, Gutman, G, Fantino, E, Chandy KG, Gargus JJ, Pulver AE (1999) Lack of linkage or association between schizophrenia and the polymorphic trinucleotide repeat within the KCNN3 gene on chromosome 1q21. Am J Med Genet 88:348-351.

Austin CP, Holder DJ, Ma L, Mixson LA, Caskey CT (1999) Mapping of hKCa3 to chromosome 1q21 and investigation of linkage of CAG repeat polymorphism to schizophrenia. Mol Psychiatry 4:261-266.

Berridge MJ (1998) Neuronal calcium signaling. Neuron 21:13-26.

Blatz AL, Magleby KL (1986) Single apamin-blocked Ca-activated K+ channels of small conductance in cultured rat skeletal muscle. Nature 323:718-720.

Bond CT, Maylie J, Adelman JP (1999) Small-conductance calciumactivated potassium channels. Ann NY Acad Sci 868:370-378.

Bonnet-Brilhault F, Laurent C, Campion D, Thibaut F, Lafargue C, Charbonnier F, Deleuze JF, Menard JF, Jay M, Petit M, Frebourg T, Mallet J (1999) No evidence for involvement of KCNN3 (hSKCa3) potassium channel gene in familial and isolated cases of schizophrenia. Eur J Hum Genet 7:247-250.

Chandy KG, Fantino E, Wittekindt O, Kalman K, Tong LL, Ho TH, Gutman GA, Crocq MA, Ganguli R, Nimgaonkar V, Morris-
Rosendahl DJ, Gargus JJ (1998) Isolation of a novel potassium channel gene hSKCa3 containing a polymorphic CAG repeat: a candidate for schizophrenia and bipolar disorder? Mol Psychiatry 3:32-37.

Chiodo LA, Bannon MJ, Grace AA, Roth RH, Bunney BS (1984) Evidence for the absence of impulse-regulating somatodendritic and synthesis-modulating nerve terminal autoreceptors on subpopulations of mesocortical dopamine neurons. Neuroscience 12:1-16.

Dunnett SB, Bjorklund A (1999) Prospects for new restorative and neuroprotective treatments in Parkinson's disease. Nature 399:A32-A39.

Fiorillo CD, Williams JT (1998) Glutamate mediates an inhibitory postsynaptic potential in dopamine neurons. Nature 394:78-82.

Fiorillo CD, Williams JT (2000) Selective inhibition by adenosine of mGluR IPSPs in dopamine neurons after cocaine treatment. J Neurophysiol 83:1307-1314.

Franz O, Liss B, Neu A, Roeper J (2000) Single-cell mRNA expression of HCN1 correlates with a fast gating phenotype of hyperpolarizationactivated cyclic nucleotide-gated ion channels (Ih) in central neurons. Eur J Neurosci 12:2685-2693.

Gargus JJ, Fantino E, Gutman GA (1998) A piece in the puzzle: an ion channel candidate gene for schizophrenia. Mol Med Today 4:518-524.

Gariano RF, Tepper JM, Sawyer SF, Young SJ, Groves PM (1989) Mesocortical dopaminergic neurons. 1. Electrophysiological properties and evidence for soma-dendritic autoreceptors. Brain Res Bull 22:511-516.

Goldman-Rakic PS (1999) The physiological approach: functional architecture of working memory and disordered cognition in schizophrenia. Biol Psychiatry 46:650-661.

Gonzalez-Hernandez T, Rodriguez M (2000) Compartmental organization and chemical profile of dopaminergic and GABAergic neurons in the substantia nigra of the rat. J Comp Neurol 421:107-135.

Grace AA (1991). Phasic versus tonic dopamine release and the modulation of dopamine system responsivity: a hypothesis for the etiology of schizophrenia. Neuroscience 41:1-24.

Grace AA, Bunney BS (1984b) The control of firing pattern in nigral dopamine neurons: burst firing. J Neurosci 4:2877-2890.

Grace AA, Bunney BS (1984a) The control of firing pattern in nigral dopamine neurons: single spike firing. J Neurosci 4:2866-2876.

Grace AA, Onn SP (1989) Morphology and electrophysiological properties of immunocytochemically identified rat dopamine neurons recorded in vitro. J Neurosci 9:3463-3481.

Grenhoff J, Ugedo L, Svensson TH (1988) Firing patterns of midbrain dopamine neurons: differences between A9 and A10 cells. Acta Physiol Scand 134:127-132.

Gu X, Blatz AL, German DC (1992) Subtypes of substantia nigra dopaminergic neurons revealed by apamin: autoradiographic and electrophysiological studies. Brain Res Bull 28:435-440.

Hirschberg B, Maylie J, Adelman JP, Marrion NV (1998) Gating of recombinant small-conductance $\mathrm{Ca}$-activated $\mathrm{K}+$ channels by calcium. J Gen Physiol 111:565-581.

Hirschberg B, Maylie J, Adelman JP, Marrion NV (1999) Gating properties of single SK channels in hippocampal CA1 pyramidal neurons. Biophys J 77:1905-1913.

Ishii TM, Maylie J, Adelman JP (1997a) Determinants of apamin and d-tubocurarine block in SK potassium channels. J Biol Chem 272:23195-23200.

Ishii TM, Silvia C, Hirschberg B, Bond CT, Adelman JP, Maylie J (1997b) A human intermediate conductance calcium-activated potassium channel. Proc Natl Acad Sci USA 94:11651-11656.

Kang Y, Kitai ST (1993) Calcium spike underlying rhythmic firing in dopaminergic neurons of the rat substantia nigra. Neurosci Res 18:195-207.

Kirkpatrick K, Bourque CW (1996) Activity dependence and functional role of the apamin-sensitive $\mathrm{K}+$ current in rat supraoptic neurones in vitro. J Physiol (Lond) 494:389-398.

Kita T, Kita H, Kitai ST (1986) Electrical membrane properties of rat substantia nigra compacta neurons in an in vitro slice preparation. Brain Res 372:21-30.

Kitai ST, Shepard PD, Callaway JC, Scroggs R (1999) Afferent modulation of dopamine neuron firing patterns. Curr Opin Neurobiol 9:690-697.

Koch C (1999) Biophysics of computation: information processing in single neurons, Ed 1. Oxford: Oxford UP.

Kohler M, Hirschberg B, Bond CT, Kinzie JM, Marrion NV, Maylie J, Adelman JP (1996) Small-conductance, calcium-activated potassium channels from mammalian brain. Science 273:1709-1714.

Lacey MG, Mercuri NB, North RA (1989) Two cell types in rat substantia nigra zona compacta distinguished by membrane properties and the actions of dopamine and opioids. J Neurosci 9:1233-1241.

Lambolez B, Audinat E, Bochet P, Crepel F, Rossier J (1992) AMPA receptor subunits expressed by single Purkinje cells. Neuron 9:247-258.

Lancaster B, Adams PR (1986) Calcium-dependent current generating the afterhyperpolarization of hippocampal neurons. J Neurophysiol $55: 1268-1282$.

Li YX, Bertram R, Rinzel J (1996) Modeling $N$-methyl-D-aspartateinduced bursting in dopamine neurons. Neuroscience 71:397-410. 
Liss B, Bruns R, Roeper J (1999a) Alternative sulfonylurea receptor expression defines metabolic sensitivity of K-ATP channels in dopaminergic midbrain neurons. EMBO J 18:833-846.

Liss B, Neu A, Roeper J (1999b) The weaver mouse gain-of-function phenotype of dopaminergic midbrain neurons is determined by coactivation of wvGirk2 and K-ATP channels. J Neurosci 19:8839-8848.

Mercuri NB, Bonci A, Calabresi P, Stratta F, Stefani A, Bernardi G (1994) Effects of dihydropyridine calcium antagonists on rat midbrain dopaminergic neurones. Br J Pharmacol 113:831-838.

Mourre C, Schmid-Antomarchi H, Hugues M, Lazdunski M (1984) Autoradiographic localization of apamin-sensitive $\mathrm{Ca}^{2+}$-dependent $\mathrm{K}+$ channels in rat brain. Eur J Pharmacol 100:135-136.

Mueller AL, Brodie MS (1989) Intracellular recording from putative dopamine-containing neurons in the ventral tegmental area of Tsai in a brain slice preparation. J Neurosci Methods 28:15-22.

Nedergaard S, Flatman JA, Engberg I (1993) Nifedipine- and omegaconotoxin-sensitive $\mathrm{Ca}^{2+}$ conductances in guinea- pig substantia nigra pars compacta neurones. J Physiol (Lond) 466:727-747.

Nelson EL, Liang CL, Sinton CM, German DC (1996) Midbrain dopaminergic neurons in the mouse: computer-assisted mapping. J Comp Neurol 369:361-371.

Nemoto C, Hida T, Arai R (1999) Calretinin and calbindin-D28k in dopaminergic neurons of the rat midbrain: a triple-labeling immunohistochemical study. Brain Res 846:129-136.

Oliver D, Klocker N, Schuck J, Baukrowitz T, Ruppersberg JP, Fakler B (2000) Gating of $\mathrm{Ca}^{2+}$-activated $\mathrm{K}+$ channels controls fast inhibitory synaptic transmission at auditory outer hair cells. Neuron 26:595-601.

Overton PG, Clark D (1997) Burst firing in midbrain dopaminergic neurons. Brain Res Brain Res Rev 25:312-334.

Pedarzani P, Storm JF (1993) PKA mediates the effects of monoamine transmitters on the $\mathrm{K}+$ current underlying the slow spike frequency adaptation in hippocampal neurons. Neuron 11:1023-1035.

Pedarzani P, Mosbacher J, Rivard A, Cingolani LA, Oliver D, Stocker M, Adelman JP, Fakler B (2000) Control of electrical activity in central neurons by modulating the gating of small conductance $\mathrm{Ca}^{2+}$-activated K+ channels. J Biol Chem 276:9762-9769.

Ping HX, Shepard PD (1996) Apamin-sensitive $\mathrm{Ca}^{(2+)}$-activated $\mathrm{K}+$ channels regulate pacemaker activity in nigral dopamine neurons. NeuroReport 7:809-814.

Richards CD, Shiroyama T, Kitai ST (1997) Electrophysiological and immunocytochemical characterization of GABA and dopamine neurons in the substantia nigra of the rat. Neuroscience 80:545-557.

Romey G, Hugues M, Schmid-Antomarchi H, Lazdunski M (1984) Apamin: a specific toxin to study a class of $\mathrm{Ca}^{2+}$-dependent $\mathrm{K}+$ channels. J Physiol (Lond) 79:259-264.

Sah P (1996) $\mathrm{Ca}^{(2+)}$-activated $\mathrm{K}+$ currents in neurones: types, physiological roles and modulation. Trends Neurosci 19:150-154.

Sanghera MK, Trulson ME, German DC (1984) Electrophysiological properties of mouse dopamine neurons: in vivo and in vitro studies. Neuroscience 12:793-801.

Seutin V, Johnson SW, North RA (1993) Apamin increases NMDAinduced burst-firing of rat mesencephalic dopamine neurons. Brain Res 630:341-344.

Seutin V, Massotte L, Scuvee-Moreau J, Dresse A (1998) Spontaneous apamin-sensitive hyperpolarizations in dopaminergic neurons of neonatal rats. J Neurophysiol 80:3361-3364.

Seutin V, Mkahli F, Massotte L, Dresse A (2000) Calcium release from internal stores is required for the generation of spontaneous hyperpolarizations in dopaminergic neurons of neonatal rats. J Neurophysiol 83:192-197.

Shah M, Haylett DG (2000) The pharmacology of hSK1 Ca ${ }^{2+}$-activated $\mathrm{K}+$ channels expressed in mammalian cell lines. $\mathrm{Br} \mathrm{J}$ Pharmacol 129:627-630.

Shepard PD, Bunney BS (1988) Effects of apamin on the discharge properties of putative dopamine-containing neurons in vitro. Brain Res 463:380-384.
Shepard PD, Bunney BS (1991) Repetitive firing properties of putative dopamine-containing neurons in vitro: regulation by an apaminsensitive $\mathrm{Ca}^{(2+)}$-activated $\mathrm{K}+$ conductance. Exp Brain Res $86: 141-150$

Shepard PD, German DC (1988) Electrophysiological and pharmacological evidence for the existence of distinct subpopulations of nigrostriatal dopaminergic neuron in the rat. Neuroscience 27:537-546.

Shepard PD, Stump D (1999) Nifedipine blocks apamin-induced bursting activity in nigral dopamine-containing neurons. Brain Res 817:104-109.

Spanagel R, Weiss F (1999) The dopamine hypothesis of reward: past and current status. Trends Neurosci 22:521-527.

Stocker M, Pedarzani P (2000) Differential distribution of three $\mathrm{Ca}^{(2+)}$ activated $\mathrm{K}(+)$ channel subunits, SK1, SK2, and SK3, in the adult rat central nervous system. Mol Cell Neurosci 15:476-493.

Stocker M, Krause M, Pedarzani P (1999) An apamin-sensitive $\mathrm{Ca}^{2+}$ activated $\mathrm{K}+$ current in hippocampal pyramidal neurons. Proc Natl Acad Sci USA 96:4662-4667.

Storm JF (1989) An after-hyperpolarization of medium duration in rat hippocampal pyramidal cells. J Physiol (Lond) 409:171-190.

Strobaek D, Jorgensen TD, Christophersen P, Ahring PK, Olesen SP (2000) Pharmacological characterization of small-conductance $\mathrm{Ca}^{(2+)}$ activated $\mathrm{K}(+)$ channels stably expressed in HEK 293 cells. $\mathrm{Br} \mathrm{J}$ Pharmacol 129:991-999.

Stuart GJ, Dodt HU, Sakmann B (1993) Patch-clamp recordings from the soma and dendrites of neurons in brain slices using infrared video microscopy. Pflügers Arch 423:511-518.

Svensson TH (2000) Dysfunctional brain dopamine systems induced by psychotomimetic NMDA-receptor antagonists and the effects of antipsychotic drugs. Brain Res Brain Res Rev 31:320-329.

Syme CA, Gerlach AC, Singh AK, Devor DC (2000) Pharmacological activation of cloned intermediate- and small-conductance $\mathrm{Ca}^{(2+)}$-activated $\mathrm{K}(+)$ channels. Am J Physiol Cell Physiol 278: C570-C581.

Tkatch T, Baranauskas G, Surmeier DJ (1998) Basal forebrain neurons adjacent to the globus pallidus co-express GABAergic and cholinergic marker mRNAs. NeuroReport 9:1935-1939.

Tkatch T, Baranauskas G, Surmeier DJ (2000) Kv4.2 mRNA abundance and A-type $\mathrm{K}(+)$ current amplitude are linearly related in basal ganglia and basal forebrain neurons. J Neurosci 20:579-588.

Vergara C, Latorre R, Marrion NV, Adelman JP (1998) Calciumactivated potassium channels. Curr Opin Neurobiol 8:321-329.

Verhoeff NP (1999) Radiotracer imaging of dopaminergic transmission in neuropsychiatric disorders. Psychopharmacology (Berl) 147:217-249.

Vincent JB, Paterson AD, Strong E, Petronis A, Kennedy JL (2000) The unstable trinucleotide repeat story of major psychosis. Am J Med Genet 97:77-97.

Wilson CJ, Callaway JC (2000) Coupled oscillator model of the dopaminergic neuron of the substantia nigra. J Neurophysiol 83:3084-3100.

Wilson CJ, Young SJ, Groves PM (1977) Statistical properties of neuronal spike trains in the substantia nigra: cell types and their interactions. Brain Res 136:243-260.

Xia XM, Fakler, B, Rivard, A, Wayman, G, Johnson-Pais, T, Keen JE, Ishii, T, Hirschberg, B, Bond CT, Lutsenko, S, Maylie, J, Adelman JP (1998) Mechanism of calcium gating in small-conductance calciumactivated potassium channels. Nature 395:503-507.

Yung WH, Hausser MA, Jack JJ (1991) Electrophysiology of dopaminergic and non-dopaminergic neurones of the guinea-pig substantia nigra pars compacta in vitro. J Physiol (Lond) 436:643-667.

Zhang, L, Weiner JL, Valiante TA, Velumian AA, Watson PL, Jahromi SS, Schertzer, S, Pennefather, P, Carlen PL (1994) Whole-cell recording of the $\mathrm{Ca}^{(2+)}$-dependent slow afterhyperpolarization in hippocampal neurones: effects of internally applied anions. Pflügers Arch 426: $247-253$. 